ISSN 2073-4352

www.mdpi.com/journal/crystals

Review

\title{
Advances in the Growth and Characterization of Relaxor-PT-Based Ferroelectric Single Crystals
}

\author{
Jun Luo ${ }^{1, *}$ and Shujun Zhang ${ }^{2}$ \\ 1 TRS Technologies, Inc., State College, PA 16801, USA \\ 2 Material Research Institute, Pennsylvania State University, University Park, PA 16802, USA; \\ E-Mail: soz1@psu.edu
}

* Author to whom correspondence should be addressed; E-Mail: jun@trstechnologies.com; Tel.: +1-814-238-7485; Fax: +1-814-238-7539.

Received: 29 April 2014; in revised form: 7 May 2014 / Accepted: 4 June 2014 /

Published: 16 July 2014

\begin{abstract}
Compared to $\mathrm{Pb}\left(\mathrm{Zr}_{1-x} \mathrm{Ti}_{x}\right) \mathrm{O}_{3}$ (PZT) polycrystalline ceramics, relaxor-PT single crystals offer significantly improved performance with extremely high electromechanical coupling and piezoelectric coefficients, making them promising materials for piezoelectric transducers, sensors and actuators. The recent advances in crystal growth and characterization of relaxor-PT-based ferroelectric single crystals are reviewed in this paper with emphases on the following topics: (1) the large crystal growth of binary and ternary relaxor-PT-based ferroelectric crystals for commercialization; (2) the composition segregation in the crystals grown from such a solid-solution system and possible solutions to reduce it; (3) the crystal growth from new binary and ternary compositions to expand the operating temperature and electric field; (4) the crystallographic orientation dependence and anisotropic behaviors of relaxor-PT-based ferroelectriccrystals; and (5) the characterization of the dielectric, elastic and piezoelectric properties of the relaxor-PT-based ferroelectriccrystals under small and large electric fields.
\end{abstract}

Keywords: relaxor-based ferroelectric crystals; composition segregation; anisotropic behavior; piezoelectric properties; dielectric properties 


\section{Introduction}

The ferroelectric system, $\mathrm{Pb}\left(\mathrm{Zr}_{1-x} \mathrm{Ti}_{x}\right) \mathrm{O}_{3}(\mathrm{PZT})$, which was discovered 60 years ago [1], is playing an important role in modern transducer, sensor and actuator industries. PZT ceramics, with a composition lying near a morphotropic phase boundary (MPB) between the tetragonal and rhombohedral phases, exhibit anomalously high dielectric and piezoelectric properties as a result of enhanced polarizability arising from the coupling between two equivalent energy states, allowing optimum domain reorientation during the poling process [2-4]. After the discovery of PZT, searching for alternative MPB systems other than that found in PZT led to extensive studies of relaxor-based ferroelectrics and their solid solutions with $\mathrm{PbTiO}_{3}(\mathrm{PT})$. A schematic ternary phase-diagram depicting MPBs in PZT and relaxor-PT systems is shown in Figure 1 [5]. Lead-based relaxor materials are complex perovskites with the general formula $\mathrm{Pb}\left(\mathrm{B}_{\mathrm{I}} \mathrm{B}_{\mathrm{II}}\right) \mathrm{O}_{3}\left(\mathrm{~B}_{\mathrm{I}}=\mathrm{Mg}^{2+}, \mathrm{Zn}^{2+}, \mathrm{Ni}^{2+}, \mathrm{Sc}^{3+}, \mathrm{Fe}^{3+}, \mathrm{Yb}^{3+}\right.$, $\mathrm{In}^{3+}$, etc., $\mathrm{B}_{\mathrm{II}}=\mathrm{Nb}^{5+}, \mathrm{Ta}^{5+}, \mathrm{W}^{6+}$, etc.), which characteristically show a broad and frequency dispersive dielectric maxima [4,6-8]. A variety of different relaxor-PT systems have been extensively studied in the form of single crystals [9-11]. Relaxor-PT single crystals, such as $\mathrm{Pb}\left(\mathrm{Zn}_{1 / 3} \mathrm{Nb}_{2 / 3}\right) \mathrm{O}_{3}-\mathrm{PbTiO}_{3}$ (PZN-PT) and $\mathrm{Pb}\left(\mathrm{Mg}_{1 / 3} \mathrm{Nb}_{2 / 3}\right) \mathrm{O}_{3}-\mathrm{PbTiO}_{3}$ (PMN-PT) have been found to offer significant high performance with electromechanical coupling $\left(k_{33}\right)>90 \%$ and piezoelectric coefficients $\left(d_{33}\right)>1500 \mathrm{pC} / \mathrm{N}$ in contrast to PZT polycrystalline ceramics $\left(k_{33} \sim 75 \%, d_{33} \sim 400-600 \mathrm{pC} / \mathrm{N}\right)$, making them promising candidates for medical and sonar transducers, industrial sensors and solid-state actuators, which need high sensitivity and a broad bandwidth [4,12-14]. In this paper, major advances in the crystal growth and characterization of relaxor-PT-based piezoelectric single crystals are reviewed with focuses on large-sized crystal growth process development and composition modification to improve the thermal and electrical stability of piezoelectric, dielectric and elastic properties.

Figure 1. Ternary phase-diagram depicting morphotropic phase boundaries (MPBs) in $\mathrm{Pb}\left(\mathrm{Zr}_{1-x} \mathrm{Ti}_{x}\right) \mathrm{O}_{3}$ (PZT) and relaxor-PT systems. Reprinted with permission from [5]. Copyright 1994 the Japan Society of Applied Physics.

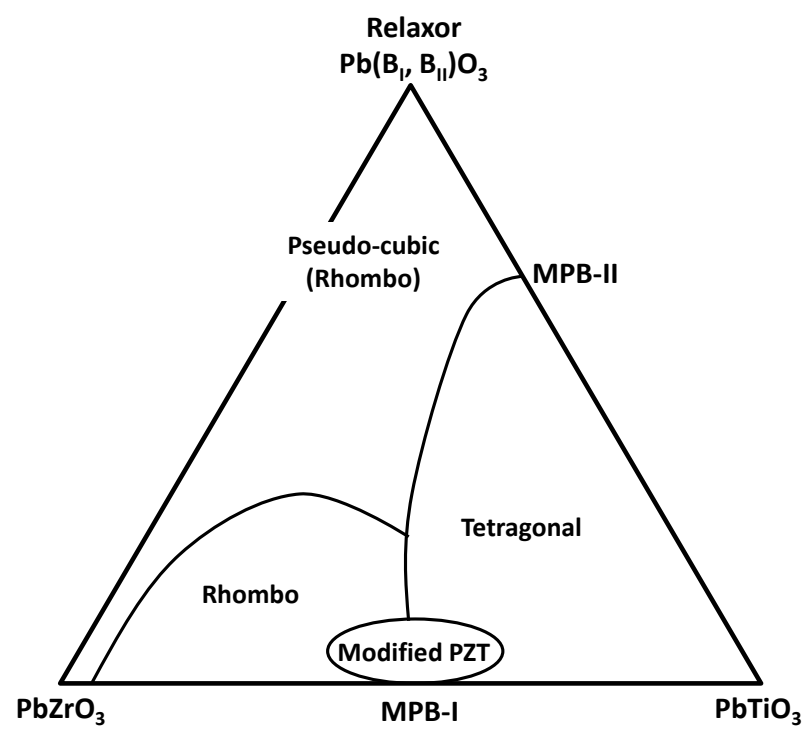




\section{Relaxor-PT-Based Ferroelectric Crystal Growth}

\subsection{PZN-PT and PMN-PT}

It is always a great challenge to grow single crystals of complex compounds. The successful growth of PMN-PT and PZN-PT single crystals became a real breakthrough that started a new era in relaxor-PT-based ferroelectric crystal research. Binary PMN-PT and PZN-PT solid-solutions, which present a perovskite phase, can be synthesized from complex oxide systems of $\mathrm{PbO}-\mathrm{MgO}(\mathrm{ZnO})-\mathrm{Nb}_{2} \mathrm{O}_{5}-\mathrm{TiO}_{2}$. However, the formation of the parasitic pyrochlore phase was the most problematic in the crystal growth process, causing instability in crystallization and generating defects and polycrystals $[15,16]$. Several other challenges to the growth of large single crystals include volatilization of $\mathrm{PbO}$, the high melting point of the oxides and the composition segregation of the solid solutions $[15,16]$.

PMN-PT and PZN-PT crystals were first grown by the flux method, which demonstrated ultrahigh piezoelectric coefficients and strain levels with low hysteresis [4,10]. The flux method is a type of high temperature solution growth, which is based on the spontaneous nucleation that occurs when supersaturation happens in a slow cooling process. The method has been broadly adopted in the growth of new crystal materials, especially those that melt incongruently or volatilize seriously before reaching melting temperature [17]. Difficulty in crystallization orientation control, slow growth rate, small crystal size and flux inclusions are common limitations of the flux growth method. To overcome these limitations, several improved high temperature solution growth methods, including top-seeded solution growth (TSSG) and solution-Bridgman growth, have been developed based on the basic flux method for the growth of PMN-PT and PZN-PT crystals [18,19]. In top-seeded solution growth, by introducing a perovskite seed crystal into the solution, it became possible to trigger single nucleation and control the crystallization orientation to obtain large-sized single crystals. The solution-Bridgman growth combines the flux growth and the vertical Bridgman growth, which is more suitable for growing large crystals. Currently, PMN-PT and PZN-PT single crystals grown by high temperature solution methods have reached the sizes of $35 \mathrm{~mm}$ in edge length or two inches in diameter.

The effective crystal growth technologies have been explored extensively after the extraordinary piezoelectric performance of PMN-PT and PZN-PT crystals were revealed. DTA study indicated that PMN-PT melts congruently [16,20,21], suggesting the possibility of growing PMN-PT crystals from the melt directly. These studies also showed that PMN-PT has a more stable perovskite phase and exhibits less of a tendency to form the parasitic pyrochlore phase compared to PZN-PT. By pre-synthesizing PMN-PT and using sealed Pt crucibles to prevent the volatilization of $\mathrm{PbO}$ at high temperature, PMN-PT single crystals have been grown directly from the melt using the Bridgman method [22,23]. Compared to flux growth, the Bridgman technique can grow large-sized single crystal boules along specific crystallographic orientations with a higher growth rate, which can potentially reduce the cost of PMN-PT crystals, to be competitive with the high quality piezoelectric ceramics used in high-end applications.

It was indicated that the formation of inclusions/voids, spontaneous nucleation, crystallization orientation control and reduction of the composition variation are the major challenges in the growth of large-sized and high quality PMN-PT crystals by the Bridgman process [15,16,22,23]. Owing to the 
large difference in melting point and density between each oxide, especially between $\mathrm{PbO}\left(T_{\mathrm{m}}=886^{\circ} \mathrm{C}\right.$, $\left.\rho=9.53 \mathrm{~g} / \mathrm{cm}^{3}\right)$ and $\mathrm{MgO}\left(T_{\mathrm{m}}=2852{ }^{\circ} \mathrm{C}, \rho=3.58 \mathrm{~g} / \mathrm{cm}^{3}\right)$, it is usually difficult to get a homogeneousperovskite phase by directly mixing the oxides without the presence of a minor amount of the pyrochlore phase [16]. Pre-synthesized PMN-PT using a modified columbite precursor method has been proven to be the most efficient way to eliminate the pyrochlore phase [24]. In this method, instead of using oxides, $\mathrm{MgO}$ and $\mathrm{Nb}_{2} \mathrm{O}_{5}$, columbite precursor, $\mathrm{MgNb}_{2} \mathrm{O}_{6}$, which has a similar structure to the perovskite phase, was synthesized by solid-state reaction and used as the raw material to bypass the intermediate pyrochlore phase reaction. The high-quality PMN-PT compound can also be synthesized by different routes, including the coprecipitation method [25] and the molten salt synthesis method [26]. The inclusions/voids formation, dendrite growth and polycrystal formation are all largely attributed to the pyrochlore phase formed in the raw material; however, such defects can be also induced by other factors, such as the non-stoichiometry of the raw material, impurities and too fast of a growth rate.

Since PMN-PT crystal exhibits the highest piezoelectric response along the $<001>$ orientation, $<001>$-cut wafers have become highly demanded [16]. Owing to the inevitable axial composition segregation of this solid-solution in the Bridgman process [22,27], highly uniform (001) wafers can only be produced by successful and repeatable $<001>$-oriented crystal growth. However, since PMN-PT presents the slowest growth rate along the low-index $<001>$ orientation $\left(\mathrm{R}_{<001>}<\mathrm{R}_{<110>}<\mathrm{R}_{<111>}\right)$, the Bridgman growth of bulk PMN-PT crystal along $<001>$ becomes the most challenging. Spontaneous nucleation is apt to happen and dominate the crystallization process, forming polycrystals instead of a single crystal. The growth process in Bridgman growth has to be finely controlled to avoid the spontaneous nucleation on the solid-liquid interface.

Significant progress has been made in the Bridgman growth of PMN-PT in recent years. High-quality and large-sized PMN-PT crystals without macro-defects have been successfully grown along different crystallographic orientations, including $<001>,<110>$ and $<111>$. Currently, $<001>$-oriented PMN-PT crystals with a 100-mm diameter are commercially available. Figure 2 shows a 100-mm diameter crystal boule grown along $<001>$ and the $(001)$ wafers cut from it.

Figure 2. A $100-\mathrm{mm}$ diameter $\mathrm{Pb}\left(\mathrm{Mg}_{1 / 3} \mathrm{Nb}_{2 / 3}\right) \mathrm{O}_{3}-\mathrm{PbTiO}_{3}$ (PMN-PT) crystal grown along $<001>$ (a) and 100-mm diameter (001) wafers (in comparison with 75-mm diameter ones); (b) courtesy of TRS Technologies Inc., State College, PA, USA.

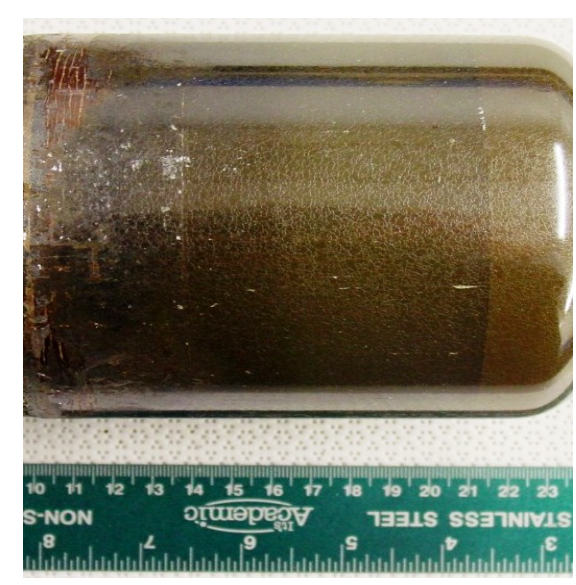

(a)

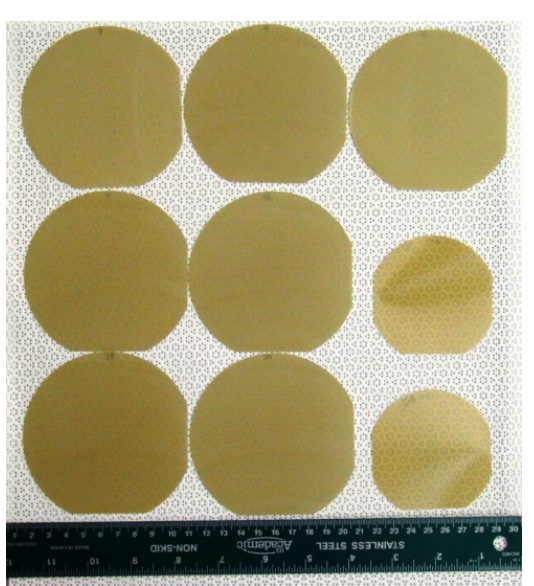

(b) 
Although the Bridgman method is a very promising technique, the composition segregation issue has to be addressed. Since PMN-PT is a complete solid-solution system, as shown by its high temperature phase diagram, it inevitably exhibits an inhomogeneous composition distribution along crystal boules grown by the Bridgman method [22,27], resulting in the variation of dielectric and piezoelectric properties along the growth direction. Even though the composition variation along the growth direction can be restrained to some degree by applying a higher growth rate and a lower axial temperature gradient across the solid-liquid interface, it can never be eliminated due to the thermodynamic nature of the solid solution system [27]. The composition distribution can be simulated by a well-established equation used for describing the composition segregation behavior in solid solution systems during the normal solidification process [17]:

$$
c_{\mathrm{s}}=k_{\mathrm{e}} c_{0}(1-g)^{k_{\mathrm{e}}-1}
$$

Where $k_{\mathrm{e}}$ is the effective segregation coefficient, $C_{\mathrm{s}}$ and $C_{0}$ the solute concentration in the crystal and the starting melt and $g$ the solidified fraction.

It was verified by chemical analysis that, except for $\mathrm{Pb}$, all other elements in PMN-PT crystals exhibit composition segregation during crystal growth, with effective segregation coefficients of $\mathrm{Nb}$ and $\mathrm{Mg}$ larger than one, while that of $\mathrm{Ti}$ is smaller than one. Figure 3 compares the piezoelectric property $\left(d_{33}\right)$ variation with the composition distributions measured by EPMA and simulated by the above equation [28], which shows the region between two peaks roughly corresponding to a PT $\left(\mathrm{PbTiO}_{3}\right)$ concentration of $31 \%$ to $35 \%$, which is basically consistent with the broad MPB region between rhombohedral and tetragonal phases proposed by Guo et al. [29,30]. The simulated effective segregation coefficient of $\mathrm{Ti}$ in this run was around 0.83. Studies show that the mixed phases, including metastable ferroelectric monoclinic $\left(\mathrm{FE}_{\mathrm{m}}\right)$ and ferroelectric orthorhombic $\left(\mathrm{FE}_{\mathrm{o}}\right)$ phases, are possibly present in this region [29-31].

Figure 3. Comparison of piezoelectric property $\left(d_{33}\right)$ variation with the composition distribution. Reprinted with permission from [28]. Copyright 2008 CRC Press.

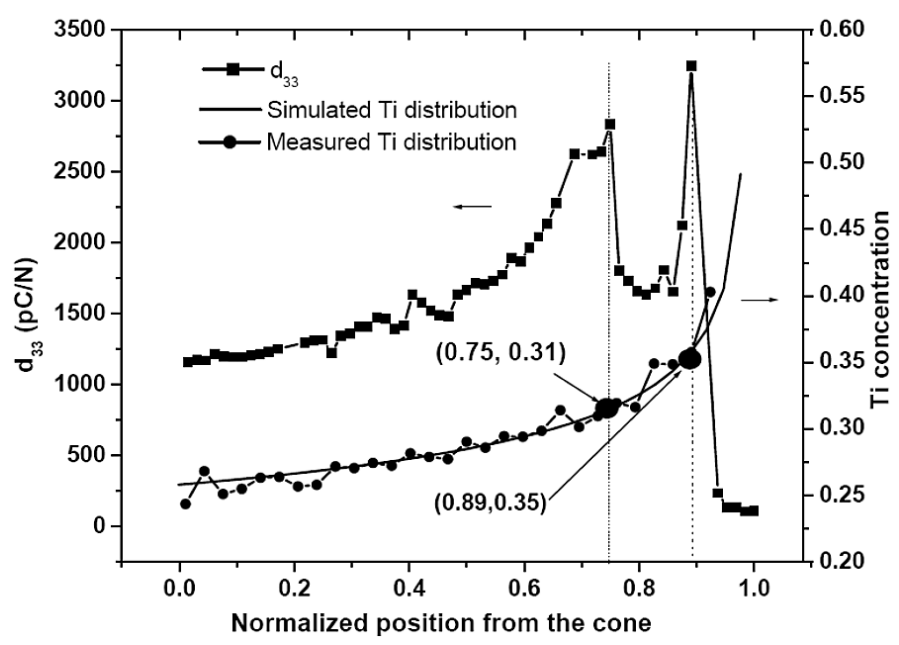

As described above, the existence of the composition segregation-induced longitudinal property variation is one of the main disadvantages of Bridgman growth. Although the $<001>$-oriented Bridgman growth can produce desirable (001) wafers with very high lateral uniformity in each wafer, it cannot 
eliminate the wafer-to-wafer variation. Usually, only a portion of each boule possesses the required PT composition range that meets the desired piezoelectric and dielectric properties. To further reduce or even eliminate the composition segregation in PMN-PT crystals, several innovative crystal growth methods were proposed, including, zone leveling [16], continuous feeding Bridgman growth [32] and solid-state crystal growth [28,33].

Zone leveling, a type of zone-melting crystal growth method, has been developed to produce a uniform, or level, distribution of solute in polycrystals and single crystals in many applications [34], which was proposed as an alternative method to prevent composition segregation in PMN-PT crystal growth [16]. Theoretically, zone leveling can produce a flat composition distribution except for the initial and last frozen regions (zones). The zone melting growth of PMN-PT crystals was conducted in both RF induction heated and resistance heated furnaces [27,28]. Constant composition at PT $=32 \%$ was observed over $\sim 60 \mathrm{~mm}$ of total boule length $(\sim 80 \mathrm{~mm})$ in a zone-leveled boule compared with the constantly changing composition usually observed in Bridgman grown crystals [27].

As proposed, continuous feeding Bridgman is a modified Bridgman method, in which PMN powder or pellets are charged slowly into the melt during crystal growth to keep the concentration of $\mathrm{Mg}, \mathrm{Nb}$ and Ti constant. The challenge of this method is to minimize the thermal disturbance to the melt, as well as to prevent $\mathrm{PbO}$ from evaporation during the feeding operation. This technique was demonstrated successfully by the growth of $80-\mathrm{mm}$ diameter PMN-PT crystals [35]. Curie temperature $\left(T_{\mathrm{C}}\right)$ was controlled to a range of $130-138{ }^{\circ} \mathrm{C}$ in a $116-\mathrm{mm}$-long portion of such a crystal, which is much narrower than that in the crystals grown by the regular Bridgman technique (usually $120-160{ }^{\circ} \mathrm{C}$ ). As $T_{\mathrm{C}}$ is strongly correlated to the composition, it is indicated that the crystal possesses a much narrower composition distribution along the length.

Solid-state crystal growth (SSCG) is based on an abnormal grain growth in the sintering of polycrystalline ceramics, in which a small number of grains is grow quickly by consuming surrounding fine matrix grains [28]. In SSCG of a PMN-PT crystal, a small BZT $\left(\mathrm{Ba}\left(\mathrm{Zr}_{0.1} \mathrm{Ti}_{0.9}\right) \mathrm{O}_{3}\right)$ single crystal is used as a seed to control the nucleation of abnormal grains, so that a large single crystal can be obtained in the polycrystalline matrix. Since the polycrystalline ceramic matrix is not melted, the composition segregation does not happen. The other advantages that the SSCG method provides include low process temperature, no need for Pt crucibles and crystal growth of incongruently melting compositions. However, in this process, it is hard to completely eliminate the porosity in the crystals, which may affect the mechanical and optical properties [33]. Currently, PMN-PT crystals larger than $50 \times 50 \times 10 \mathrm{~mm}^{3}$ can be produced by the SSCG method [28].

\subsection{High $T_{C}$ Relaxor-PT Binary Crystals}

Even though large-sized and high-quality PMN-PT crystals can be grown directly from the melt, their low ferroelectric-to-ferroelectric phase transition temperatures and low coercive field restrict their applications largely. The piezoelectric/dielectric properties of rhombohedral-phase PMN-PT crystals have a strong temperature dependence. For instance, PMN-29\%PT exhibit a $52 \%$ change in the dielectric constant from room temperature to $55{ }^{\circ} \mathrm{C}$. This change negatively affects the transducer impedance and matching circuitry and, therefore, the power delivery system. Furthermore, the rhombohedral-to-tetragonal ferroelectric phase transition temperature $\left(T_{\mathrm{rt}}\right)$ for PMN-PT crystals with 
near MPB compositions is as low as $85{ }^{\circ} \mathrm{C}$ to $95{ }^{\circ} \mathrm{C}$, which becomes the maximum applicable temperature. In addition to the temperature stability, PMN-PT crystals have a coercive field as low as $2-2.5 \mathrm{kV} / \mathrm{cm}$, limiting the amplitude of the driving field and the power output. High Curie temperature piezoelectric crystals are desired to expand the operational temperature and electric field, to reduce the properties' temperature dependence and to increase the acoustic power output [36].

Table 1 lists broadly investigated binary relaxor-PT systems, among which the $\mathrm{Pb}\left(\mathrm{Sc}_{1 / 2} \mathrm{Nb}_{1 / 2}\right)$ $\mathrm{O}_{3}-\mathrm{PbTiO}_{3}$ (PSN-PT), $\mathrm{Pb}\left(\mathrm{In}_{1 / 2} \mathrm{Nb}_{1 / 2}\right) \mathrm{O}_{3}-\mathrm{PbTiO}_{3}(\mathrm{PIN}-\mathrm{PT})$ and $\mathrm{Pb}\left(\mathrm{Yb}_{1 / 2} \mathrm{Nb}_{1 / 2}\right) \mathrm{O}_{3}-\mathrm{PbTiO}_{3}(\mathrm{PYN}-\mathrm{PT})$ were found to possess relatively high Curie temperatures near their MPB compositions [5,37,38]. Henceforth, numerous research has focused on these binary systems in single crystal form in order to achieve high performance over a wide temperature range [24,39-50].

Table 1. Morphotropic phase boundaries in perovskite $\mathrm{Pb}\left(\mathrm{B}_{\mathrm{I}} \mathrm{B}_{\mathrm{II}}\right) \mathrm{O}_{3}-\mathrm{PT}$ ceramic systems.

\begin{tabular}{lccc}
\hline \multicolumn{1}{c}{ Binary System } & PT $(\boldsymbol{x})$ at MPB & $\boldsymbol{T}_{\mathbf{C}}\left({ }^{\circ} \mathbf{C}\right)$ at MPB & $\boldsymbol{T}_{\mathrm{R}-\mathrm{T}}\left({ }^{\circ} \mathbf{C}\right)$ at MPB \\
\hline$(1-x) \mathrm{Pb}\left(\mathrm{Zn}_{1 / 3} \mathrm{Nb}_{2 / 3}\right) \mathrm{O}_{3}-x \mathrm{PbTiO}_{3}(\mathrm{PZN}-\mathrm{PT})$ & $\sim 0.09$ & $\sim 180$ & 95 \\
$(1-x) \mathrm{Pb}\left(\mathrm{Mg}_{1 / 3} \mathrm{Nb}_{2 / 3}\right) \mathrm{O}_{3}-x \mathrm{PbTiO}_{3}(\mathrm{PMN}-\mathrm{PT})$ & $\sim 0.33$ & $\sim 150$ & 80 \\
$(1-x) \mathrm{Pb}\left(\mathrm{Ni}_{1 / 3} \mathrm{Nb}_{2 / 3}\right) \mathrm{O}_{3}-x \mathrm{PbTiO}_{3}(\mathrm{PNN}-\mathrm{PT})$ & $\sim 0.40$ & $\sim 130$ & - \\
$(1-x) \mathrm{Pb}\left(\mathrm{Co}_{1 / 3} \mathrm{Nb}_{2 / 3}\right) \mathrm{O}_{3}-x \mathrm{PbTiO}_{3}(\mathrm{PCN}-\mathrm{PT})$ & $\sim 0.38$ & $\sim 250$ & - \\
$(1-x) \mathrm{Pb}\left(\mathrm{Sc}_{1 / 2} \mathrm{Nb}_{1 / 2}\right) \mathrm{O}_{3}-x \mathrm{PbTiO}_{3}(\mathrm{PSN}-\mathrm{PT})$ & $\sim 0.43$ & $\sim 260$ & 100 \\
$(1-x) \mathrm{Pb}\left(\mathrm{Sc}_{1 / 2} \mathrm{Ta}_{1 / 2}\right) \mathrm{O}_{3}-x \mathrm{PbTiO}_{3}(\mathrm{PST}-\mathrm{PT})$ & $\sim 0.45$ & $\sim 205$ & - \\
$(1-x) \mathrm{Pb}\left(\mathrm{Fe}_{1 / 2} \mathrm{Nb}_{1 / 2}\right) \mathrm{O}_{3}-x \mathrm{PbTiO}_{3}(\mathrm{PFN}-\mathrm{PT})$ & $\sim 0.07$ & $\sim 140$ & - \\
$(1-x) \mathrm{Pb}\left(\mathrm{In}_{1 / 2} \mathrm{Nb}_{1 / 2}\right) \mathrm{O}_{3}-x \mathrm{PbTiO}_{3}(\mathrm{PIN}-\mathrm{PT})$ & $\sim 0.37$ & $\sim 320$ & 120 \\
$(1-x) \mathrm{Pb}\left(\mathrm{Yb}_{1 / 2} \mathrm{Nb}_{1 / 2}\right) \mathrm{O}_{3}-x \mathrm{PbTiO}_{3}(\mathrm{PYN}-\mathrm{PT})$ & $\sim 0.50$ & $\sim 360$ & 160 \\
$(1-x) \mathrm{Pb}\left(\mathrm{Mg}_{1 / 2} \mathrm{~W}_{1 / 2}\right) \mathrm{O}_{3}-x \mathrm{PbTiO}_{3}$ (PMW-PT) & $\sim 0.55$ & $\sim 60$ & - \\
$(1-x) \mathrm{Pb}\left(\mathrm{Co}_{1 / 2} \mathrm{~W}_{1 / 2}\right) \mathrm{O}_{3}-x \mathrm{PbTiO}_{3}(\mathrm{PCW}-\mathrm{PT})$ & $\sim 0.45$ & $\sim 310$ & - \\
\hline
\end{tabular}

PSN-PT single crystals with MPB compositions were successfully grown by the flux method using $\mathrm{PbO}-\mathrm{B}_{2} \mathrm{O}_{3}$ as the flux [39-41]. The growth temperature range and $\mathrm{B}_{2} \mathrm{O}_{3}$ ratio in the flux are deemed very important because of the perovskite stability. The perovskite crystal size obtained was found to be 2-15 mm in length. PSN-33\%PT crystals were reported to possess a high Curie temperature, $T_{\mathrm{C}} \sim 206{ }^{\circ} \mathrm{C}$ (30-50 ${ }^{\circ} \mathrm{C}$ higher than PMN-PT and PZN-PT systems), while the electromechanical coupling factor $\left(k_{33}\right)$ and dielectric constant were found to be only $72 \%$ and 960 , respectively.

Single crystals of PIN-PT and their electromechanical properties were also studied. It was reported that PIN-28PT crystals could be grown using the flux method with $\mathrm{PbO}-\mathrm{PbF}_{2}-\mathrm{B}_{2} \mathrm{O}_{3}$. The obtained crystals were $20 \times 10 \times 5 \mathrm{~mm}^{3}$ in size, which is much larger compared to PSN-PT crystals [42]. The Curie temperature was reported to be $260{ }^{\circ} \mathrm{C}$ with a rhombohedral-to-tetragonal phase transition temperature, $T_{\mathrm{rt}}$, around $100{ }^{\circ} \mathrm{C}$. The electromechanical coupling in the longitudinal mode $\left(k_{33}\right)$ was estimated to be $85 \%$ at room temperature [42]. The same research group also reported growing PIN-PT crystals by the solution Bridgman method using $\mathrm{PbO}-\mathrm{B}_{2} \mathrm{O}_{3}$ as the flux, in which a crystal with $10 \mathrm{~mm}$ in diameter and $10 \mathrm{~mm}$ in length was obtained and the growth direction was determined along the [110] direction. The $T_{\mathrm{C}}$ and $T_{\mathrm{rt}}$ were found to be $300{ }^{\circ} \mathrm{C}$ and $120{ }^{\circ} \mathrm{C}$, respectively, for PIN-31\%PT crystals [43]. It was also reported the PIN-34\%PT crystals were grown by using PMNT31 as a seed crystal. The obtained crystals were found to have high piezoelectric coefficients $d_{33} \sim 2000 \mathrm{pC} / \mathrm{N}$ and 
electromechanical coupling $k_{33}$ of about $94 \%$, comparable to the PMN-PT system, while exhibiting higher $T_{\mathrm{C}}$ at $200^{\circ} \mathrm{C}$ [44].

For the systems mentioned above, $T_{\mathrm{C}}$ on the order of $200-300{ }^{\circ} \mathrm{C}$ has been found; however, $T_{\mathrm{rt}}$ is still in the range of only $70-120^{\circ} \mathrm{C}$. PYN-PT with MPB composition was found to possess the highest $T_{\mathrm{C}}$ of about $360^{\circ} \mathrm{C}$ among all of the lead-based relaxor-PT systems, similar to the commercial PZT5A ceramics. Piezoelectric single crystals in the PYN-PT system were grown using the flux method with $\mathrm{Pb}_{3} \mathrm{O}_{4}$ or $\mathrm{Pb}_{3} \mathrm{O}_{4} / \mathrm{B}_{2} \mathrm{O}_{3}$ as the flux. Perovskite PYN-PT solid solutions were prepared using the "wolframite process", which consists of the synthesized B-site precursor, $\mathrm{YbNbO}_{4}$, prior to reaction with $\mathrm{PbO}$ and $\mathrm{TiO}_{2}[24,45,46]$. The obtained crystals were light yellow in color and 2-8 mm in size.

Table 2 summarized the detailed dielectric and piezoelectric properties of different relaxor-PT single crystal systems, in which it can be seen that all of the single crystals possess high electromechanical coupling, except for PSN-PT. The dielectric and piezoelectric properties were found to not only depend on the composition, but also depend on the Curie temperature: the higher Curie temperature the crystal system possesses, the lower dielectric constant and piezoelectric properties were observed; however, higher coercive fields were found with higher $T_{\mathrm{C}}$.

Table 2. Detailed dielectric and piezoelectric properties of relaxor-PT single crystals.

\begin{tabular}{cccccccc}
\hline Crystal & $\boldsymbol{T}_{\mathbf{c}}\left({ }^{\circ} \mathbf{C}\right)$ & $\boldsymbol{T}_{\mathbf{R - T}}\left({ }^{\circ} \mathbf{C}\right)$ & $\boldsymbol{E}_{\mathbf{c}}(\mathbf{k V} / \mathbf{c m})$ & $K_{33}^{T}$ & $\boldsymbol{d}_{\mathbf{3 3}}(\mathbf{p C} / \mathbf{N})$ & $\boldsymbol{k}_{\mathbf{3 3}}$ & Reference \\
\hline PMN-31PT & 143 & 90 & 2.5 & 5100 & 2000 & $90 \%$ & {$[47]$} \\
PZN-4.5PT & 155 & 120 & 3.2 & 4400 & 2100 & $90 \%-91 \%$ & {$[47]$} \\
PZN-8PT & 170 & 100 & 4 & 6000 & 2500 & $93 \%$ & {$[47]$} \\
PZN-12PT & 190 & - & 8.5 & 870 & 576 & $86 \%$ & {$[48]$} \\
PSN-33PT & 206 & - & 6 & 960 & - & $72 \%$ & {$[39]$} \\
PIN-28PT & 260 & 100 & 18 & 1500 & 700 & $85 \%$ & {$[42,49]$} \\
PIN-34PT & 200 & $<100$ & - & 5000 & 2000 & $94 \%$ & {$[44]$} \\
PYN-40PT & 270 & 168 & 10 & 2700 & 1200 & $88 \%$ & {$[47]$} \\
PYN-45PT & 325 & 160 & 12.5 & 2000 & 2000 & $88 \%-90 \%$ & {$[46]$} \\
BS-57PT & 402 & 349 & 13.7 & 3000 & 1150 & $91 \%$ & {$[50]$} \\
\hline
\end{tabular}

\subsection{High $T_{C} P M N-P T-B a s e d$ Ternary Crystals}

As described above, all of the binary relaxor-PT single crystals that have a Curie temperature higher than that of PMN-PT single crystals could only be grown by the flux method. Owing to the instability of the perovskite phase of these binary compositions, commercialization of these high $T_{\mathrm{C}}$ crystals was hindered by the availability of large-sized crystals. Recently, it was demonstrated that, by adding PMN-PT into some of the high $T_{\mathrm{C}}$ binary systems, the formed PMN-PT-based ternary compositions could have a relatively stable perovskite phase, offering the possibility to grow large crystals with a pure perovskite phase [51,52].

Among the broadly studied ternary systems, substantial progress has been made on the growth of large-sized PIN-PMN-PT crystals by the Bridgman process. For the preparation of PIN-PMN-PT, both a wolframite precursor, $\mathrm{InNbO}_{4}$, and a columbite precursor, $\mathrm{MgNb}_{2} \mathrm{O}_{6}$, were firstly synthesized, respectively, by calcination of oxides at $1000-1200{ }^{\circ} \mathrm{C}$. Using these precursors, PIN-PMN-PT with a pure perovskite phase was synthesized by another calcination process at lower temperature $\left(750-900{ }^{\circ} \mathrm{C}\right)$. 
Like PMN-PT crystals, PIN-PMN-PT crystals with a pure perovskite phase form during solidification, so the crystals can be grown directly from the melt by the Bridgman process. By presenting a seed crystal, PIN-PMN-PT crystals with a diameter up to $75 \mathrm{~mm}$ have been grown along the preferred crystallographic orientations, including $\langle 001\rangle,<110\rangle$ and $\langle 111\rangle$. Figure 4 shows the as-grown PIN-PMN-PT crystals. It was found that the $T_{\mathrm{rt}}$ and $T_{\mathrm{C}}$ of PIN-PMN-PT (26\%-36\%PIN) crystals reach 120-140 ${ }^{\circ} \mathrm{C}$ and $160-200{ }^{\circ} \mathrm{C}$, respectively, marking a $35-40{ }^{\circ} \mathrm{C}$ increase compared to PMN-PT crystals with a similar PT concentration. Furthermore, they exhibit a similar $d_{33}$ value (1100-2200 pC/N) as PMN-PT crystals, but a much higher coercive field $(4.5-6 \mathrm{kV} / \mathrm{cm})$.

Figure 4. Seventy five-millimeter and $50-\mathrm{mm}$ diameter $<001>$-oriented PIN-PMN-PT crystals grown by the Bridgman process (courtesy of TRS Technologies, Inc., State College, PA, USA).

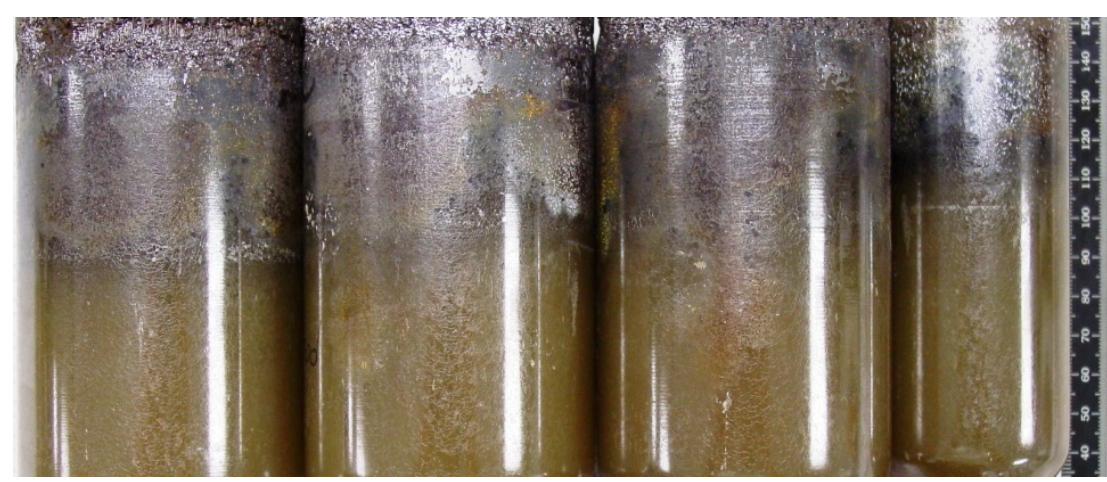

PZT ceramics have been the mainstay for high-performance piezoelectric applications. However, the attempt to grow single-crystal PZT has not been successful. So far, only very small crystals of PZT can be produced by high temperature solution growth, which cannot provide samples for complete property measurement. As PMN-PT crystals, chemically homogeneous PMN-PZT crystals were also successfully grown by the solid-state crystal growth (SSCG) process [53]. By this delicately controlled sintering process, the as-grown PMN-PZT crystals achieved a similar size and quality as SSCG-grown PMN-PT crystals. Interestingly, the $T_{\mathrm{C}}$ of all PMN-PZT crystals is approximately $200{ }^{\circ} \mathrm{C}$; however, by changing the PMN/PZ/PT ratio, $T_{\mathrm{rt}}$ could be adjusted in the range of $100-160{ }^{\circ} \mathrm{C}$, while $d_{33}$ in the range of $1000-2000 \mathrm{pC} / \mathrm{N}$ [53].

Recently, some other PMN-PT-based ternary solid solution systems, including $\mathrm{Pb}\left(\mathrm{Yb}_{1 / 2} \mathrm{Nb}_{1 / 2}\right) \mathrm{O}_{3^{-}}$ $\mathrm{Pb}\left(\mathrm{Mg}_{1 / 3} \mathrm{Nb}_{2 / 3}\right) \mathrm{O}_{3}-\mathrm{PbTiO}_{3}$ (PYN-PMN-PT), $\mathrm{Pb}\left(\mathrm{In}_{1 / 2} \mathrm{Nb}_{1 / 2}\right) \mathrm{O}_{3}-\mathrm{Pb}\left(\mathrm{Zn}_{1 / 3} \mathrm{Nb}_{2 / 3}\right) \mathrm{O}_{3}-\mathrm{PbTiO}_{3}$ (PIN-PZN-PT) and $\mathrm{Pb}\left(\mathrm{Fe}_{1 / 2} \mathrm{Nb}_{1 / 2}\right) \mathrm{O}_{3}-\mathrm{Pb}\left(\mathrm{Yb}_{1 / 2} \mathrm{Nb}_{1 / 2}\right) \mathrm{O}_{3}-\mathrm{PbTiO}_{3}$ (PFN-PYN-PT), have been investigated [54-57]. By the top-seeded solution growth (TSSG) method, crystals with compositions near an MPB have been grown, which show comparable piezoelectric properties to PMN-PT crystals, but higher Curie temperature and/or coercive field. As the TSSG method has been successfully applied to the large-scale production of some nonlinear optical crystals, such as $\beta-\mathrm{BaBO}_{4}(\mathrm{BBO})$ and $\mathrm{KTiOPO}_{4}(\mathrm{KTP})$ crystals, it is possible that it can be tailored to produce large crystals of these ternary solid solution crystals. Currently, PYN-PMN-PT crystals with a length and width over $3 \mathrm{~cm}$ have been obtained by the TSSG method. As complex flux systems are required to facilitate crystallization and to achieve a high crystal growth rate, the main challenge in the TSSG growth of crystals of these complex ternary compositions is to repeatedly produce high quality crystals that maintain consistent properties. 
Table 3 summarizes the major piezoelectric and dielectric properties of PMN-PT-based ternary solid solution crystals that can operate at higher temperature and a higher electric field than current state-of-the-art PMN-PT single crystals.

Table 3. Detailed dielectric and piezoelectric properties of PMN-PT-based ternary crystals.

\begin{tabular}{cccccccc}
\hline Crystal & $\boldsymbol{T}_{\mathbf{c}}\left({ }^{\circ} \mathbf{C}\right)$ & $\boldsymbol{T}_{\mathbf{R}-\mathbf{T}}\left({ }^{\circ} \mathbf{C}\right)$ & $\begin{array}{c}\boldsymbol{E}_{\mathbf{c}} \\
\mathbf{( k V / c m})\end{array}$ & $K_{33}^{T}$ & $\boldsymbol{d}_{\mathbf{3 3}}(\mathbf{p C} / \mathbf{N})$ & $\boldsymbol{k}_{\mathbf{3 3}}$ & Reference \\
\hline PMN-29PT & 135 & 96 & 2 & 5400 & 1540 & $91 \%$ & {$[58]$} \\
PMN-31PT & 143 & 90 & 2.5 & 5100 & 2000 & $90 \%$ & {$[47]$} \\
PIN-PMN-PT * & $160 \sim 200$ & $120 \sim 140$ & $4.5-6$ & $4000-5000$ & $1100-2200$ & $89 \%-93 \%$ & {$[59]$} \\
PMN-PZT ** & $190 \sim 200$ & $100 \sim 160$ & $>5$ & $3000-6000$ & $1000-2000$ & $89 \%-92 \%$ & {$[53]$} \\
20PYN-40PMN-40PT & 180 & 130 & 5.4 & 2400 & $2440-2580$ & $90.9 \%$ & {$[54]$} \\
15PYN-53PMN-32PT & 205 & 50 & 7 & 6270 & 1800 & $90 \%$ & {$[55]$} \\
30PIN-33PbZN-37PT & 236 & 175 & 14.3 & 2500 & $1900-2100$ & $86 \%$ & {$[56]$} \\
10PFN-38PYN-52PT & 325 & 155 & 10.3 & 1620 & 1100 & $70 \%$ & {$[57]$} \\
\hline
\end{tabular}

$* 26 \%-36 \%$ PIN and 28\%-32\% PT; ** Composition PMN-PZT-11 PMN-PZT-5.

\section{Relaxor-Based Ferroelectrics Crystal Characterization}

\subsection{Crystallographic Orientation Dependence of Property}

It was reported that the relaxor-PT single crystals show a strong anisotropic behavior. Thus, in this section, the dielectric, ferroelectric, piezoelectric and electromechanical properties were studied as a function of their main crystallographic orientations, i.e., along the $<001>,<110>$ and $<111>$ directions. As reported, for rhombohedral relaxor-PT single crystals, different engineered domain configurations can be obtained by poling along different crystallographic directions. Since the spontaneous polarization is along the $<111>$ crystallographic direction, a single domain can be achieved when the crystal was poled along $<111>$, and the obtained domain configuration was $1 \mathrm{R}$, while the engineered domain configurations can be labeled as $4 \mathrm{R}$ and $2 \mathrm{R}$, when polarized along the $<001>$ and $<110>$ directions, respectively [60].

Figure 5 shows the measured electric field-induced polarization (a) and strain (b) hysteresis loops for $<001>-,<110>$ - and $<111>$-oriented PMN-30\% PT crystals. The remnant polarization, $P_{\mathrm{r}}$, and coercive field, $E_{\mathrm{C}}$, were found to be dependent on the orientation. From the symmetric loops, the $P_{\mathrm{r}}$ was found to be on the order of $0.24 \mathrm{C} / \mathrm{m}^{2}, 0.34 \mathrm{C} / \mathrm{m}^{2}$ and $0.41 \mathrm{C} / \mathrm{m}^{2}$ for the $<001>,<110>$ and $<111>$ orientations, while the coercive field, $E_{\mathrm{C}}$, was on the order of $2.5 \mathrm{kV} / \mathrm{cm}, 2.9 \mathrm{kV} / \mathrm{cm}$ and $3.2 \mathrm{kV} / \mathrm{cm}$, respectively. It is known that there are eight possible polarization orientations along the pseudo-cubic $<111>$ direction for rhombohedral relaxor-PT single crystals (3-m symmetry). Upon applying an electric field, the dipoles reorientate as close as possible to the applied electric field direction. For $<001>$-poled crystals, there are four equivalent polar vectors along the $<111>$ direction, with an inclined angle of $-54.7^{\circ}$ from the poling field. The four $<111>$ domains are equivalent, with a domain-engineered configuration resulting in a macro symmetry of $4 \mathrm{~mm}$. For $<110>$-poled crystals, there are two equivalent polar vectors along the $<111>$ direction, which will rotate $35.5^{\circ}$ toward the applied field direction of $\langle 110\rangle$ with a designated domain-engineered configuration of $2 \mathrm{R}$. For this case, the macroscopic symmetry is in $\mathrm{mm}^{2}$. In contrast, there is only one polar vector along the $<111>$ 
direction for $<111>$-poled ferroelectric crystals; thus, it will form a monodomain state, $1 \mathrm{R}$, exhibiting a symmetry of $3 \mathrm{~m}$. According to the domain-engineered configurations, the polarization level derived from the hysteresis loops should correspond, in theory, to the intrinsic value along the polar axis of the monodomain crystal, $P_{\mathrm{s}}$, following $P_{\mathrm{r}<001>}=P_{\mathrm{r}<110>} / \sqrt{2}=P_{\mathrm{r}<111>} / \sqrt{3}$ [61-63]. As expected, the $P_{\mathrm{r}}$ values for the different orientations obtained from Figure 5 a corresponded well to the predicted values. From Figure $5 b$, it is seen that in the sequence of orientation, $<001>,<011>$ and $<111>$, the electric field required to reverse the domain (coercive field $E_{\mathrm{C}}$ ) increased, which is consistent with that indicated by the polarization hysteresis, while the positive strain achieved after the domain reorientation decreased.

Figure 5. Polarization hysteresis for PMN-30\% PT crystals along crystallographic orientations $<001>,<110>$ and $<111>$. Reprinted with permission from [61]. Copyright 2009 AIP Publishing.

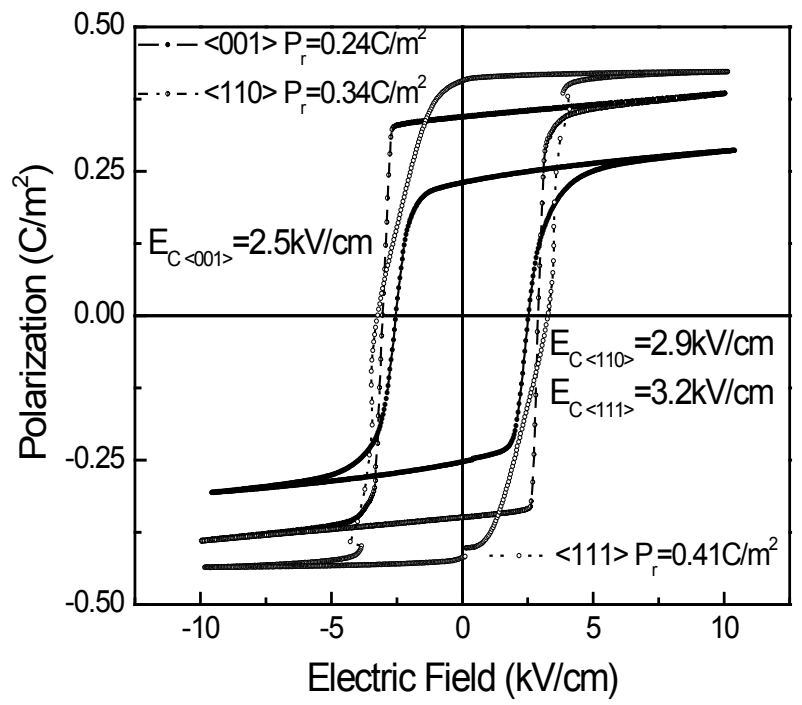

(a)

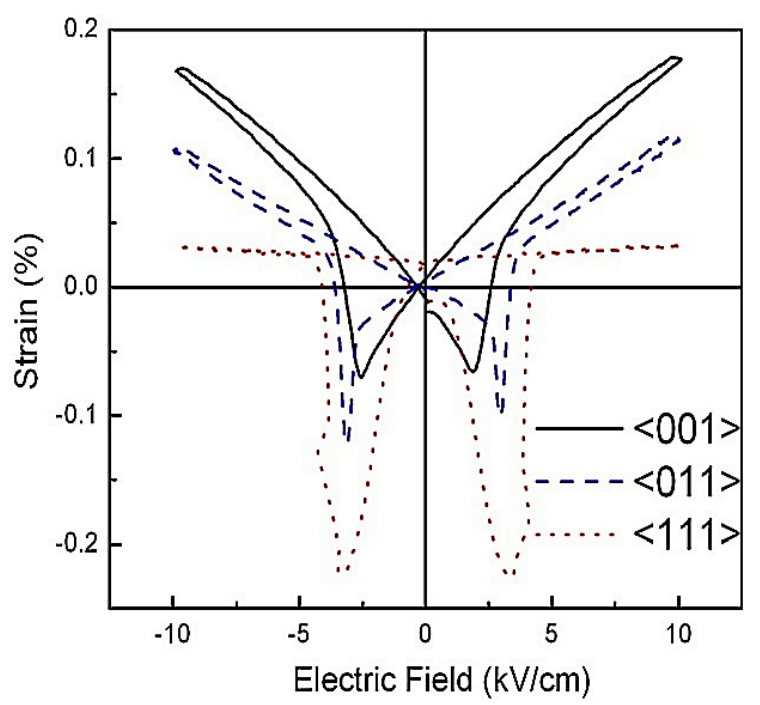

(b)

Analogous to dielectric and ferroelectric properties, the piezoelectric and electromechanical properties were also found to show anisotropic behaviors. The longitudinal piezoelectric coefficient, $d_{33}$, was found to reach its peak value when poled along crystallographic direction $<001>$, while it drops significantly when poled along the $<111>$ orientation. The transverse piezoelectric response for relaxor-PT perovskite crystals is more complicated, where it has been reported that there are four different vibration modes showing good piezoelectric characteristics. These modes are $(001) /<100>$, $(001) /<110>,(110) /<001>$ and $(110) /<\overline{1} 10>$, where the first number indicates the electrode face (perpendicular to poling direction) and the second number is the acoustic wave propagation direction [64]. It has been demonstrated that the highest transverse piezoelectric coefficients are obtained from crystals poled along $<110>$ and vibrated along the $<001>$ direction [64-68], with small signal $d_{32}$ coefficients on the order of $\sim-1500 \mathrm{pC} / \mathrm{N}$ and electromechanical coupling factor $k_{32} \sim 0.90$ in PZN-PT, PMN-PT and PMN-PZT crystals.

The main properties for longitudinal and transverse modes for PIN-PMN-PT single crystals at room temperature are listed in Table 4 [69]. The dielectric permittivity was found to be on the order of 4400, 3400 and 700 for $<001>-,<110>$ - and $<111>$-poled rhombohedral PIN-PMN-PT crystals, respectively, 
while the dielectric losses were $0.2 \%$ and $0.1 \%$, respectively. The longitudinal electromechanical coupling factor, $k_{33}$, was found to be 0.92 for $<001>$ samples, slightly higher than that of $<110>$-poled crystals $(\sim 0.91)$, but to drop significantly for $<111>$ samples, being on the order of 0.43 . The piezoelectric $d_{33}$ was on the order of $1500 \mathrm{pC} / \mathrm{N}$ for the $<001>$ cut, higher than the value for the $<110>$-oriented sample $\sim 925 \mathrm{pC} / \mathrm{N}$, while the $d_{33}$ was found to be only $\sim 90 \mathrm{pC} / \mathrm{N}$ for the $<111>$ single-domain PIN-PMN-PT crystals, as observed in other relaxor-PT systems. The typical extensional transverse modes for the perovskite ferroelectric crystal were summarized in Table 4, as well, where the first number indicates the poling direction and the second number gives the vibration orientation. Unlike $<001>$-poled samples, a large discrepancy between the piezoelectric $d_{31}$ and $d_{32}$ was observed in $<110>$-poled crystals. The optimal transverse properties were found for $(110) /<001>$ cut (polarized along $<110>$ with vibration along the $<001>$ direction), with electromechanical coupling factor $k_{32}$ on the order of 0.91 and corresponding piezoelectric $d_{32}$ on the order of $-1420 \mathrm{pC} / \mathrm{N}$.

Table 4. Longitudinal and transverse piezoelectric and electromechanical properties for $<001>$-, $<110>$ - and $<111>$-poled PIN-PMN-PT crystals.

\begin{tabular}{|c|c|c|c|c|c|c|c|}
\hline & IN-PMN-PT & & $K_{i j}$ & loss & $\boldsymbol{k}_{i j}$ & $d_{i j}(\mathrm{pC} / \mathrm{N})$ & $s_{i j}^{\mathrm{E}}\left(\mathrm{pm}^{2} / \mathbf{N}\right)$ \\
\hline \multirow{3}{*}{ Longitudinal } & & 001 & 4400 & $0.2 \%$ & 0.92 & 1500 & 68.0 \\
\hline & $i j=33$ & 110 & 3400 & $0.1 \%$ & 0.91 & 925 & 34.8 \\
\hline & & 111 & 700 & $0.1 \%$ & 0.43 & 90 & 7.0 \\
\hline \multirow{4}{*}{ Lateral } & $i j=31$ & $001 / 100$ & 4400 & $0.2 \%$ & 0.50 & -700 & 51.2 \\
\hline & $i j=31\left(45^{\circ}\right)$ & $001 / 110$ & 4400 & $0.2 \%$ & 0.81 & -800 & 25.0 \\
\hline & $i j=32$ & $110 / 001$ & 3400 & $0.1 \%$ & 0.91 & -1420 & 83.1 \\
\hline & $i j=31$ & $110 / \overline{1} 10$ & 3400 & $0.1 \%$ & 0.74 & 590 & 21.5 \\
\hline
\end{tabular}

The temperature-dependent piezoelectric and electromechanical coupling for the above-mentioned modes are shown in Figures 6 and 7. Figure 6 presents the temperature-dependent characteristics of the longitudinal electromechanical coupling and piezoelectric coefficient for $<001>$ - and $<110>$-poled PIN-PMN-PT crystals. The $k_{33}$ for $<001>$-poled crystals was found to be on the order of 0.91 at $-50{ }^{\circ} \mathrm{C}$, increasing to 0.94 at $125{ }^{\circ} \mathrm{C}$, the ferroelectric phase transition temperature, above which, the $k_{33}$ decreased to only 0.78 . In contrast, the coupling for the $<110>$-poled crystals was $>0.90$ at $-50{ }^{\circ} \mathrm{C}$, slightly increased to 0.93 at a temperature of $116{ }^{\circ} \mathrm{C}$, above which, $k_{33}$ dropped due to the rhombohedral-to-orthorhombic (R-O) phase transition. The orthorhombic-to-tetragonal (O-T) phase transition at $130{ }^{\circ} \mathrm{C}$ was also observed in the coupling measurement. The piezoelectric coefficient, $d_{33}$, followed a similar trend as found in the dielectric behavior, reaching its peak value at the ferroelectric phase transition temperatures.

Figure 7 gives the temperature-dependent behavior of the transverse electromechanical coupling and piezoelectric coefficient for $<001>$ - and $<110>$-poled samples along different vibration directions. It was found that the electromechanical coupling factors, $k_{i j}$, for different poling and vibration directions followed a similar tendency, maintaining their values in the temperature range from $-50{ }^{\circ} \mathrm{C}$ to $T_{\mathrm{F}-\mathrm{F}}$ (ferroelectric phase transition temperature). The coupling factors were found to drop sharply above the phase transition temperature, where the crystals transformed to the tetragonal and/or orthorhombic phases. The piezoelectric coefficients, $d_{31}$ and $d_{32}$ (considering the symmetry of $\mathrm{mm}^{2}$ in $<110>$-poledcrystal, the value of $d_{31}$ is assumed to be positive, while $d_{32}$ is negative, based on IEEE 
standards), showed a similar temperature-dependent behavior as found for the longitudinal mode, reaching peak values close to the ferroelectric transition temperature, above which, the transverse piezoelectric response disappeared.

Figure 6. Longitudinal electromechanical coupling $k_{33}$ (a) and piezoelectric coefficient $d_{33}$; (b) as a function of temperature for $<001>$ - and $<110>$-poled single crystals. Reprinted with permission from [69]. Copyright 2009 AIP Publishing.

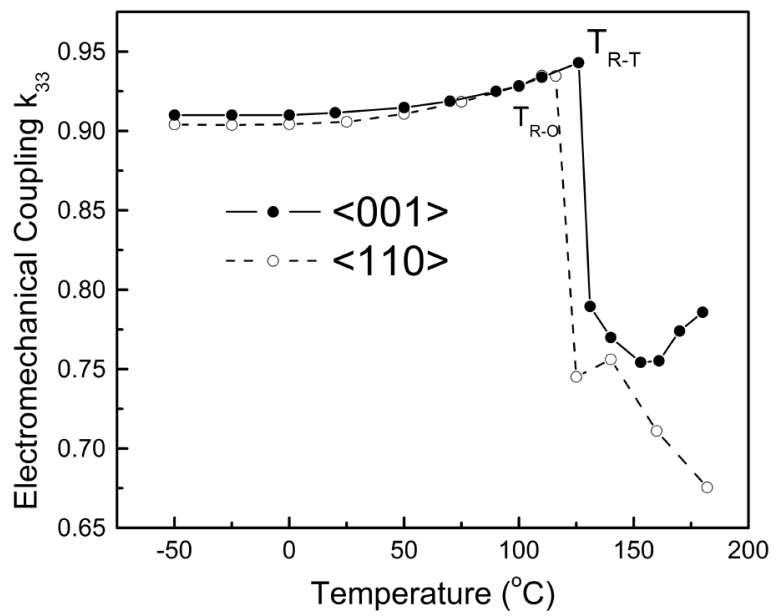

(a)

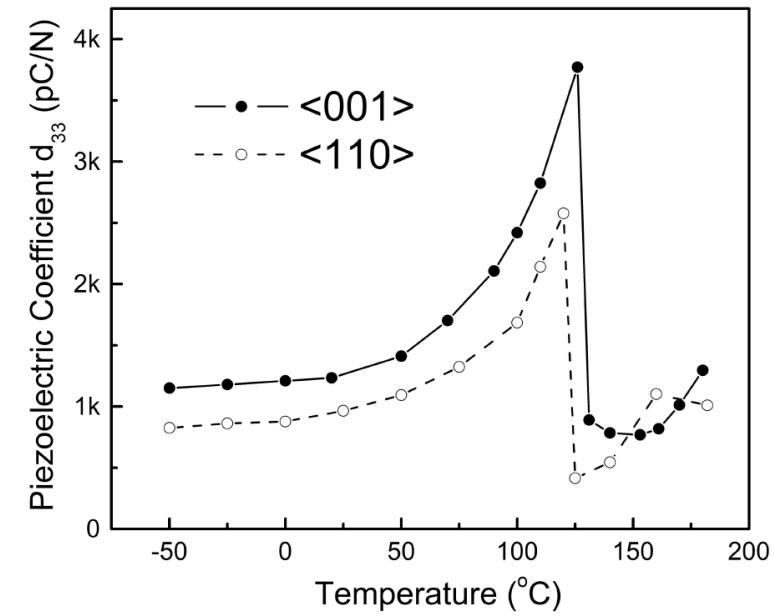

(b)

Figure 7. Transverse electromechanical coupling $k_{31} / k_{32}$ and piezoelectric $d_{31} / d_{32}$ as a function of temperature for $<001>$ - and $<110>$-poled crystals. Reprinted with permission from [69]. Copyright 2009 AIP Publishing.

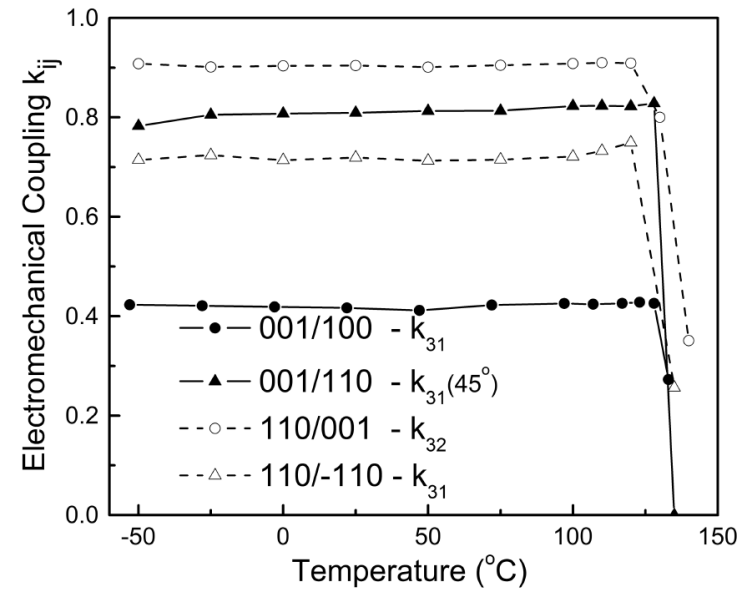

(a)

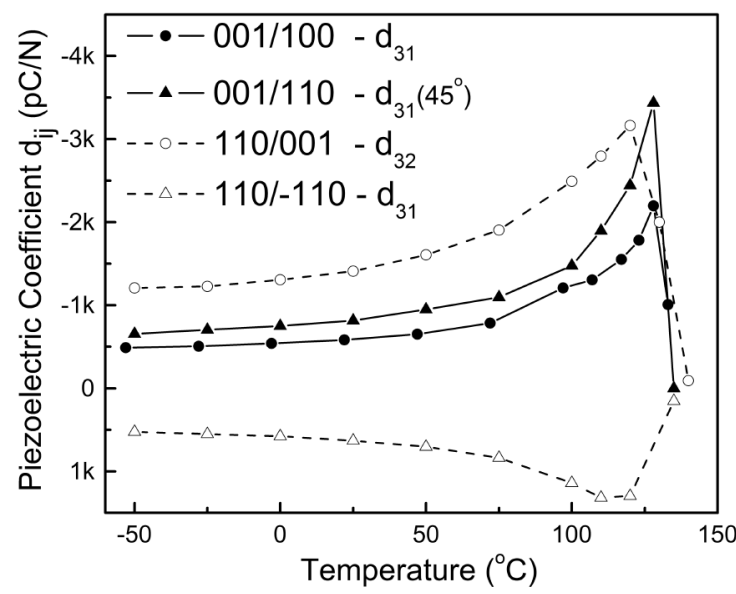

(b)

\subsection{Full Sets of Electromechanical Properties (under a Low Electric Field)}

For transducer and actuator modeling, it is very useful to obtain complete sets of electromechanical coefficients of relaxor-PT-based binary and ternary crystals. Two approaches were generally employed for such measurements. The first is the resonance method described in the IEEE standards [70]. Based upon the macro symmetries established by the domain-engineered configurations in rhombohedral relaxor-PT crystals, different sets of samples need to be prepared for the resonance measurements. For 
the lower symmetry, more samples with different orientations need to be prepared, because there are more independent physical constants that exist. Furthermore, the resonance method requires the samples to have a large aspect ratio in order to avoid mode interference. However, the resonance method is relatively simple, since all of the measurements can be done on an impedance analyzer, and the calculated coefficients can be verified by different sets of equations. The other approach is the ultrasonic method, which is performed under a non-resonance condition and, therefore, may be more accurate than the resonance method, since there is no interference among different modes. By sending longitudinal and sheer waves into crystal samples with specific orientations, all material constants can be obtained. The samples required a pair of perfectly aligned faces, but no specific aspect ratio. However, large errors may emerge for the crystals with low symmetry when deriving constants from some mixed modes. To measure and derive a complete set of electromechanical coefficients for crystals with low symmetry, it may be necessary to combine the ultrasonic and resonance methods (a hybrid method) [71].

Table 5. Elastic compliance constants, $s_{i j}\left(10^{-12} \mathrm{~m}^{2} / \mathrm{N}\right)$, and elastic stiffness constants, $c_{i j}$ $\left(10^{10} \mathrm{~N} / \mathrm{m}^{2}\right)$.

\begin{tabular}{ccccccc}
\hline Properties & $s_{11}^{E}$ & $s_{12}^{E}$ & $s_{13}^{E}$ & $s_{33}^{E}$ & $s_{44}^{E}$ & $s_{66}^{E}$ \\
\hline PMN-PT & 52.1 & -24.6 & -26.4 & 59.9 & 16.0 & 28.3 \\
PIN-PMN-PT & 49.0 & -20.0 & -26.5 & 57.3 & 15.2 & 39.4 \\
Mn:PIN-PMN-PT & 45.4 & -15.9 & -28.1 & 62.4 & 15.4 & 27.8 \\
\hline Properties & $s_{11}^{D}$ & $s_{12}^{D}$ & $s_{13}^{D}$ & $s_{33}^{D}$ & $s_{44}^{D}$ & $s_{66}^{D}$ \\
\hline PMN-PT & 41.8 & -34.8 & -3.9 & 10.3 & 14.0 & 28.3 \\
PIN-PMN-PT & 38.2 & -30.8 & -4.0 & 10.3 & 14.3 & 39.4 \\
Mn:PIN-PMN-PT & 34.4 & -26.9 & -3.9 & 9.2 & 13.9 & 27.8 \\
\hline Properties & $c_{11}^{E}$ & $c_{12}^{E}$ & $c_{13}^{E}$ & $c_{33}^{E}$ & $c_{44}^{E}$ & $c_{66}^{E}$ \\
\hline PMN-PT & 12.4 & 11.1 & 10.4 & 10.8 & 6.3 & 3.5 \\
PIN-PMN-PT & 11.9 & 10.5 & 10.4 & 11.4 & 6.6 & 2.5 \\
Mn:PIN-PMN-PT & 12.8 & 11.1 & 10.8 & 11.3 & 6.5 & 3.6 \\
\hline Properties & $c_{11}^{D}$ & $c_{12}^{D}$ & $c_{13}^{D}$ & $c_{33}^{D}$ & $c_{44}^{D}$ & $c_{66}^{D}$ \\
\hline PMN-PT & 12.6 & 11.3 & 9.3 & 16.8 & 7.1 & 3.5 \\
PIN-PMN-PT & 12.3 & 10.9 & 9.0 & 16.7 & 7.0 & 2.5 \\
Mn:PIN-PMN-PT & 13.3 & 11.7 & 9.0 & 17.0 & 7.2 & 3.6 \\
\hline
\end{tabular}

Relaxor-PT-based binary and ternary single crystals with near MPB compositions usually possess a rhombohedral phase with 3-m symmetry at a temperature lower than its rhombohedral-to-tetragonal phase transition temperature. However, when the crystals are poled along the pseudocubic [001] direction, it can be deemed as 4-mm symmetry macroscopically. The resonance method can be used to determine all of its independent electromechanical constants: six elastic, three piezoelectric and two dielectric constants. Such complete sets of constants of [001]-poled rhombohedral PMN-PT, PIN-PMN-PT and Mn:PMN-PIN-PT are listed in Tables 5-7 for comparison [72,73]. For the [011]-poled crystals (macroscopic $\mathrm{mm}^{2}$-symmetry), there are totally 17 independent electromechanical coefficients, nine elastic, five piezoelectric and three dielectric, to be determined. Either a resonance or a hybrid method 
was employed to collect the full sets of properties for [011]-poled crystals [74-76]. For the [111]-poled crystals (macroscopic 3-m symmetry), a hybrid method was usually required [77].

Table 6. Piezoelectric coefficients, $d_{i j}(\mathrm{pC} / \mathrm{N}), e_{i j}\left(\mathrm{C} / \mathrm{m}^{2}\right), g_{i j}\left(10^{-3} \mathrm{Vm} / \mathrm{N}\right)$ and $h_{i j}\left(10^{8} \mathrm{~V} / \mathrm{m}\right)$.

\begin{tabular}{ccccccc}
\hline Properties & $\boldsymbol{d}_{\mathbf{3 3}}$ & $\boldsymbol{d}_{\mathbf{3 1}}$ & $\boldsymbol{d}_{\mathbf{1 5}}$ & $\boldsymbol{e}_{\mathbf{3 3}}$ & $\boldsymbol{e}_{\mathbf{3 1}}$ & $\boldsymbol{e}_{\mathbf{1 5}}$ \\
\hline PMN-PT & 1540 & -699 & 164 & 22.3 & -3.9 & 10.3 \\
PIN-PMN-PT & 1320 & -634 & 105 & 18.6 & -4.8 & 6.9 \\
Mn:PIN-PMN-PT & 1341 & -609 & 133 & 16.8 & -5.2 & 8.6 \\
\hline Properties & $\boldsymbol{g}_{\mathbf{3 3}}$ & $\boldsymbol{g}_{\mathbf{3 1}}$ & $\boldsymbol{g}_{\mathbf{1 5}}$ & $\boldsymbol{h}_{\mathbf{3 3}}$ & $\boldsymbol{h}_{\mathbf{3 1}}$ & $\boldsymbol{h}_{\mathbf{1 5}}$ \\
\hline PMN-PT & 31.8 & -15.4 & 9.9 & 26.2 & -8.4 & 7.0 \\
PIN-PMN-PT & 35.6 & -17.0 & 8.8 & 28.9 & -7.4 & 6.5 \\
Mn:PIN-PMN-PT & 39.7 & -18.1 & 11.3 & 34.2 & -10.7 & 8.3 \\
\hline
\end{tabular}

Table 7. Electromechanical coupling factors, $k_{i j}$, and dielectric constants, $\varepsilon_{i j}\left(\varepsilon_{0}\right)$.

\begin{tabular}{cccccc}
\hline Properties & $\boldsymbol{k}_{\mathbf{3 3}}$ & $\boldsymbol{k}_{\mathbf{3 1}}$ & $\boldsymbol{k}_{\mathbf{1 5}}$ & $\boldsymbol{k}_{\mathbf{t}}$ & $\boldsymbol{k}_{\mathbf{3 1}}\left(\mathbf{4 5}{ }^{\circ} \mathbf{C}\right)$ \\
\hline PMN-PT & 0.89 & 0.44 & 0.27 & 0.56 & 0.77 \\
PIN-PMN-PT & 0.91 & 0.47 & 0.25 & 0.57 & 0.80 \\
Mn: PIN-PMN-PT & 0.92 & 0.49 & 0.31 & 0.58 & 0.80 \\
\hline Properties & $\varepsilon_{33}^{\mathrm{T}}$ & $\boldsymbol{\varepsilon}_{11}^{\mathrm{T}}$ & $\boldsymbol{\varepsilon}_{33}^{\mathrm{S}}$ & $\varepsilon_{11}^{\mathrm{s}}$ & \\
\hline PMN-PT & 5400 & 1560 & 910 & 1340 & \\
PIN-PMN-PT & 4200 & 1335 & 729 & 1200 & - \\
Mn: PIN-PMN-PT & 3811 & 1326 & 553 & 1169 & \\
\hline
\end{tabular}

\subsection{Characterization under a High Electric Field and High Mechanical Pressure}

High-power underwater transducers and high-intensity focused ultrasound (HIFU) transducers may be driven under a large electric field and operated under high mechanical prestress [78,79]. These systems are operated over a short time duration; however, a very high source level and bandwidth may be required. To prevent the piezoelectric materials from going into a tensile state under the application of a high driving electric field, it is common practice to prestress the piezoelectric elements by employing a compressive uniaxial prestress upon them. However, the material property may change under the high mechanical prestress, due to the nonlinear effects of the ferroelectric materials. It is therefore important to determine not only the small signal characteristics, but also whether the materials maintain the bandwidth and linear performance under a high driving field and a prestress condition. In recent years, more studies have been done on relaxor-PT crystals, including PMN-PT, pure and Mn-doped PIN-PMN-PT crystals, under a combination of static compressive stress and high electric field [80-86]. The performance of relaxor-PT crystals under dynamic compressive stress has also been evaluated, but only under a small electric field $[87,88]$.

The $<001>$-poled relaxor-PT crystals possess extremely high $k_{33}$ and $d_{33}$, so the longitudinal extension mode is very attractive for high power transducer design. Figure 8 shows the strain-electric field (S-E) loops and extracted $d_{33}$ measured under the unipolar electric field with constant amplitude $( \pm 12 \mathrm{kV} / \mathrm{cm}) /$ frequency $(1 \mathrm{~Hz})$ when compressive prestress was applied to manganese $(\mathrm{Mn})$-doped rhombohedral PIN-PMN-PT crystal sample along the poling direction $(<001>)$. It is indicated that the 
crystal sample produced higher strain under higher uniaxial pressure with the cost of increased nonlinear loss (as suggested by the area of the strain-field hysteresis loops).

Figure 8. The strain-electric field (S-E) loops (a) and extracted $d_{33} v s$. prestress (b) under a unipolar electric field (Mn:PIN-PMN-PT crystal in the rhombohedral phase).

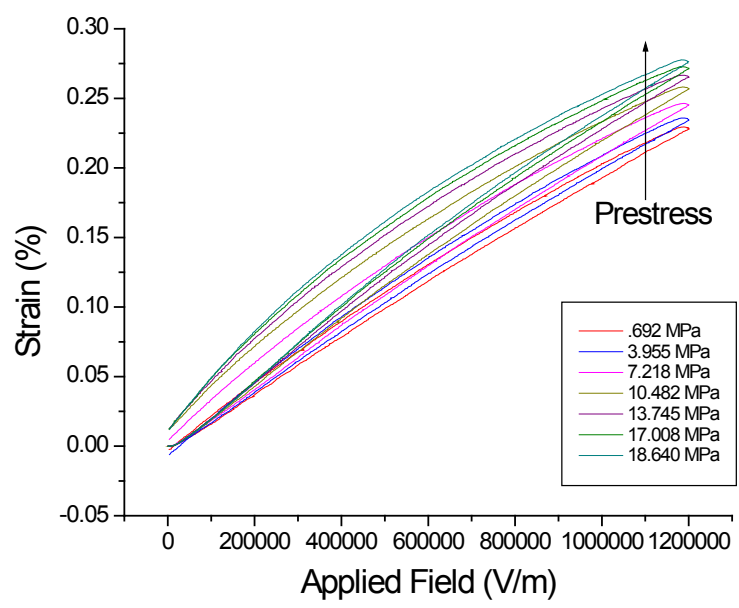

(a)

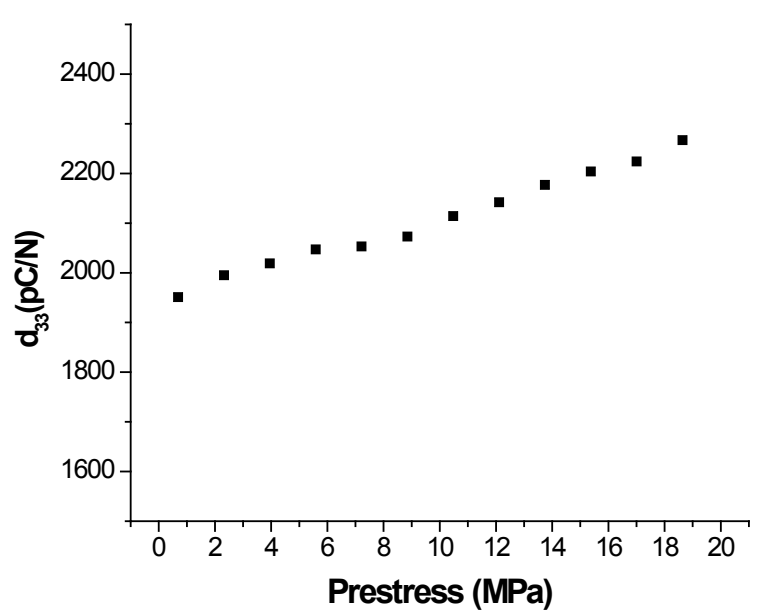

(b)

In high power transducer design, bipolar electric field (AC field) is often applied to drive the piezoelectric elements in the transducers, so it is necessary to evaluate the stability of the relaxor-PT crystals under uniaxial stress in such a driving condition. Figure 9 shows the strain-electric field (S-E) loops measured by applying an AC electric field to a Mn-doped rhombohedral PIN-PMN-PT crystal sample under $0 \mathrm{MPa}$ (a) or $10 \mathrm{MPa}$ (b) compressive prestress, respectively [86]. Under 0MPa prestress (Figure 9a), when the amplitude of the $\mathrm{AC}$ field is equal to or smaller than $5 \mathrm{kV} / \mathrm{cm}$ (roughly equal to its coercive field), the crystal sample showed a linear strain-field relationship with no concern of depoling/repoling. Beyond $5 \mathrm{kV} / \mathrm{cm}$, the strain showed a more nonlinear response. When the AC field increased to $10 \mathrm{kV} / \mathrm{cm}$, typical "butterfly"-shaped S-E loops occurred, indicating that domain reversal happened under each cycle of the AC field. Under $10 \mathrm{MPa}$ prestress (Figure 9b), the negative strain peaks became rounded, as well as the maximum negative strain reduced sharply to nearly zero [86]. As a result, the coercive field declined sharply, which means that a much lower electric field and less energy are required to reverse the domains (depole/repole the crystal). In this measurement, depoling/repoling was initiated by an AC field with an amplitude of $2 \mathrm{kV} / \mathrm{cm}$, which suggests that, if the crystal is driven by a low-frequency AC field under certain prestress, domain reversal-caused nonlinearity in the strain response may limit the amplitude of the driving AC field. For $<001>$-poled relaxor-PT crystals, as the compressive prestress aligns in the same direction as the electric field used for poling the crystal, it tends to destabilize the $4 \mathrm{R}$ domain configuration. However, it was demonstrated that the $4 \mathrm{R}$ domain configuration can be stabilized by a DC bias field applied in the same direction as that of the poling field. As shown in Figure 10, when a positive DC bias field was applied to the same crystal, the centers of the strain-field response loops were shifted toward the positive side of the electric field axis [86]. It is quite obvious that the range of the driving AC field, in which the crystal exhibited a linear strain response, was expanded to $\pm 4 \mathrm{kV} / \mathrm{cm}$ or $\pm 6 \mathrm{kV} / \mathrm{cm}$, respectively, when $\mathrm{a}+2 \mathrm{kV} / \mathrm{cm}$ or $+4 \mathrm{kV} / \mathrm{cm}$ DC bias was applied. The results indicated that the reduction of the linear 
range of strain response caused by compressive prestress is recoverable if a positive DC bias is applied to the crystal.

Figure 9. S-E loops measured under a bipolar electric field and $0 \mathrm{MPa}$ (a) and $10 \mathrm{MPa}$ (b) uniaxial prestress (Mn:PIN-PMN-PT crystal in rhombohedral phase). Reprinted with permission from [86]. Copyright 2013 IEEE.

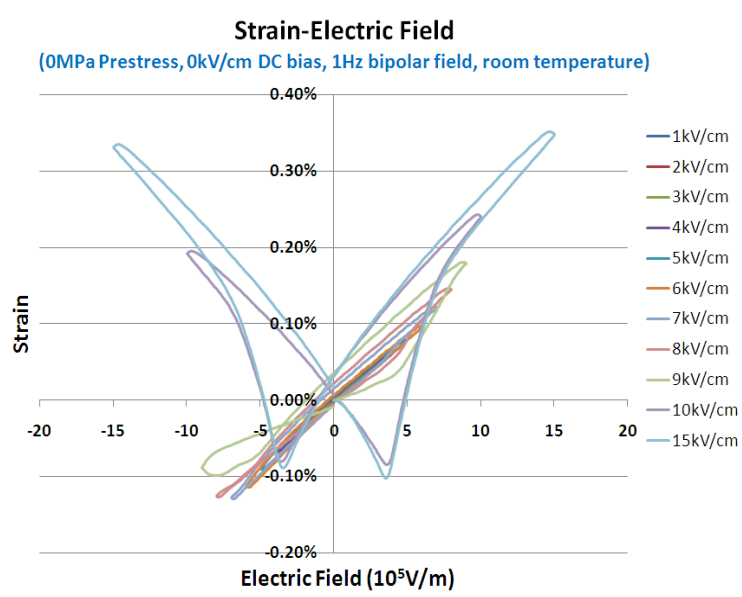

(a)

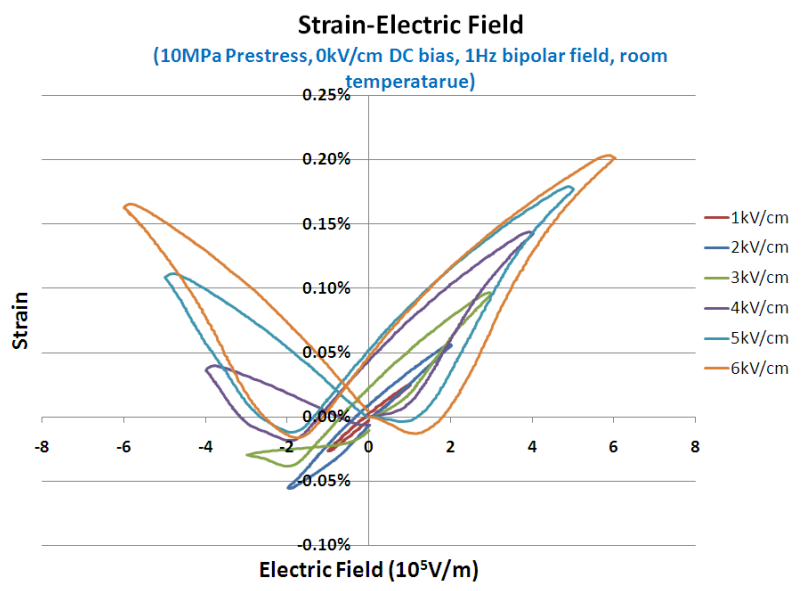

(b)

Figure 10. S-E loops of the same crystal sample as in Figure 9 measured under $10 \mathrm{MPa}$ prestress and $2 \mathrm{kV} / \mathrm{cm}$ (a) and $4 \mathrm{kV} / \mathrm{cm}$ (b) external DC bias, respectively. Reprinted with permission from [86]. Copyright 2013 IEEE.

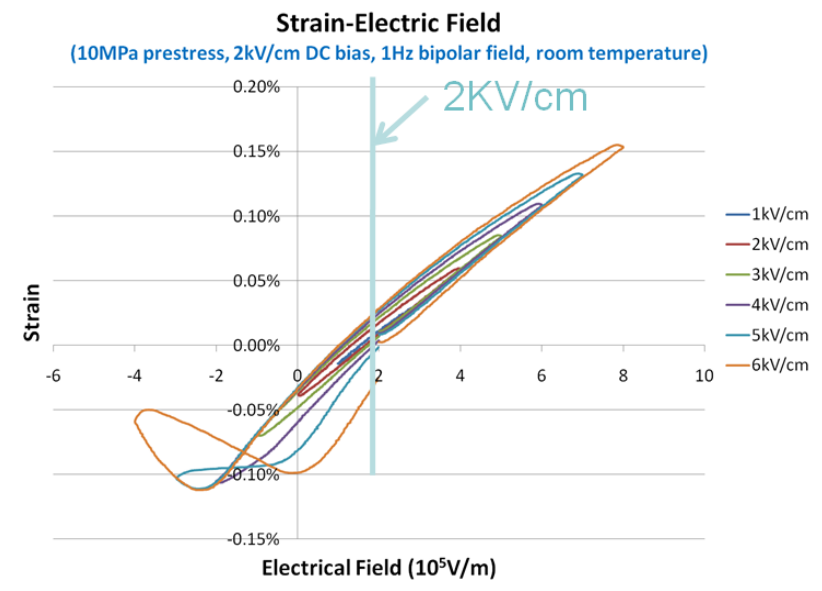

(a)

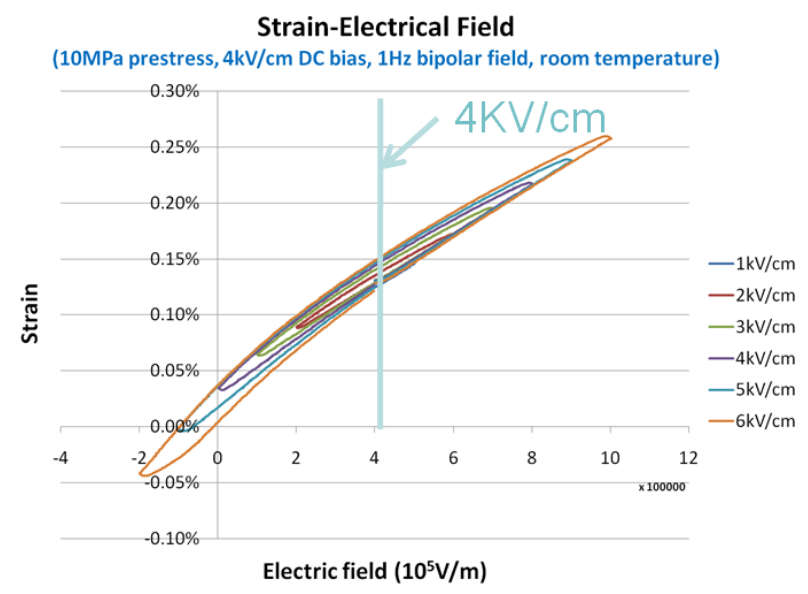

(b)

The $<110>$-poled relaxor-PT crystals have become more and more attractive for high power transducer design in recent years. When the relaxor-PT crystals operate in the $<110>$-poled transverse mode ( 32 mode, vibration along $<001>$ ), they possess very high $d_{32}$ and $k_{32}$ values; meanwhile, as the crystals are poled and driven through the thickness rather than the length, the required electric field to drive them is much lower than that for the 33 mode. Recent high field measurement also shows that $<110>$-poled relaxor-PT crystals may be more stable under the compressive prestress applied along their length (transverse compressive prestress). This study suggested that the transverse compressive 
prestress will help stabilize the poling state until the electric field becomes large enough to induce the reversible rhombohedral-to-tetragonal phase transition [85].

Figure 11 shows the bipolar strain behavior of Mn:PIN-PMN-PT rhombohedral crystals at $5 \mathrm{kV} / \mathrm{cm}$ $\mathrm{AC}$ field and various stress levels [85]. It was found that all of the strain curves for the $<110>$-poled Mn:PIN-PMN-PT rhombohedra crystal are linear and non-hysteretic, demonstrating that no domain reversal occurs at $5 \mathrm{kV} / \mathrm{cm}$. On the contrary, domain reversal happened at an AC field as low as $2 \mathrm{kV} / \mathrm{cm}$ for the $<001>$-poled Mn:PIN-PMN-PT crystal when it was under longitudinal compressive prestress, as implied by Figure $9 \mathrm{~b}$.

Figure 11. Bipolar strain behavior for Mn:PIN-PMN-PT crystals under different prestress levels. Reprinted with permission from [85]. Copyright 2013 AIP Publishing.

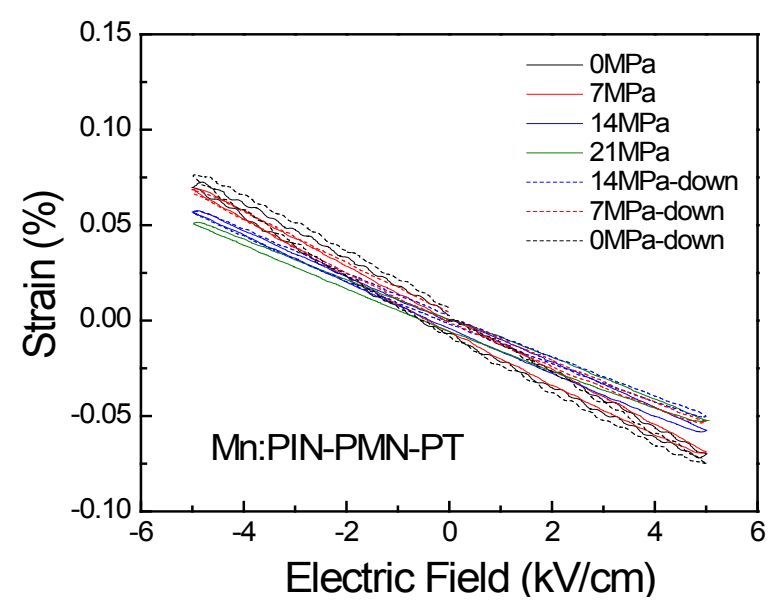

\section{Conclusions}

The successful flux growth of PMN-PT and PZN-PT single crystals started a new era in the exploration of the complex relaxor-based ferroelectric crystals. It is discovered that a variety of binary relaxor-PT and ternary relaxor-relaxor-PT/relaxor-PZ-PT crystals with claimed MPB compositions possess superior dielectric and piezoelectric properties to the conventional PZT ceramics, offering substantial advantages, such as a broad bandwidth, high sensitivity and/or high strain level for piezoelectric transduction and actuation applications [89].

In recent years, the vertical Bridgman growth of the large PMN-PT crystals led to a true breakthrough in the commercialization of relaxor-PT crystals. Currently, high-quality PMN-PT crystals with diameters up to $100 \mathrm{~mm}$ have become commercially available. However, as composition segregation is inevitable in the Bridgman growth method, further efforts are taken to improve the longitudinal composition homogeneity by applying alternative crystal growth techniques, including zone leveling, continuous feeding Bridgman growth and solid-state crystal growth.

To expand the operational temperature and electric field, a broad variety of binary relaxor-PT systems were investigated, among which, the PSN-PT, PIN-PT and PYN-PT with near MPB compositions were found to possess phase transition temperatures and coercive fields much higher than PMN-PT crystals. However, the obstacles encountered in the growth of large crystals hindered the further development of high Curie temperature $\left(T_{\mathrm{C}}\right)$, binary relaxor-PT crystals. In recent years, it was demonstrated that, by adding PMN-PT into some of the high $T_{\mathrm{C}}$ binary systems, the formed 
PMN-PT-based ternary systems could have a relatively stable perovskite phase, offering the possibility of growing large crystals with a pure perovskite phase. Among the broadly studied ternary systems, substantial progress has been made on the growth of large PIN-PMN-PT crystals by the Bridgman process. PIN-PMN-PT crystals with a $75-\mathrm{mm}$ diameter have become commercially available recently.

Compared to PZT ceramics, one of the distinguishing characteristics of the relaxor-based ferroelectric crystals is the strong anisotropy of their properties, which imposes new challenges in crystal characterization, as well as offering new opportunities for device design. The investigation of the orientation dependence of the rhombohedral relaxor-PT crystals indicated that, for the longitudinal mode (33 mode), the electromechanical coupling of $<001>$-poled crystals shows a similar value to that of $<110>$-poled crystals; however, the piezoelectric coefficient of $<001>$-poled crystal is much higher. For the transverse modes ( $d_{31}$ and $d_{32}$ modes), significant anisotropy was observed for $<110>$-poled crystals. Optimal transverse properties were found for the crystals polarized through $<110>$ with vibration along $<001>$ (32 mode), possessing values of electromechanical coupling and the piezoelectric coefficient similar to those of the $<001>$-poled longitudinal mode. Another challenge in the characterization of relaxor-PT crystals is that their properties can be influenced largely by multiple factors, including temperature, preloading stress and electric field, especially when the crystals are engaged in applications that require a high power output. It was observed that uniaxial compressive prestress, which is usually applied to the crystal elements in high power devices to prevent them from fracturing under tensile stress, strongly affects the piezoelectric performance of the relaxor-PT-based crystals along different poling orientations. However, systematic studies are needed in this critical field to determine the operational domains of these crystals for high power applications.

\section{Acknowledgments}

The authors thank the Office of Naval Research (ONR) for the financial support through SBIR and STTR programs.

\section{Author Contributions}

The original work in this paper was done by both authors, with Jun Luo focusing on the crystal growth and Shujun Zhang focusing on the characterization. The paper was written by Jun Luo through discussion with Shujun Zhang.

\section{Conflicts of Interest}

The authors declare no conflict of interest.

\section{References}

1. Sawaguchi, E. Ferroelectricity versus antiferroelectricity in the solid solutions of $\mathrm{PbZrO}_{3}$ and $\mathrm{PbTiO}_{3}$. J. Phys. Soc. Jpn. 1953, 8, 615-629.

2. Jaffe, B.; Cook, W.R.; Jaffe, H. Piezoelectric Ceramics; Academic: London, UK, 1971. 
3. Noheda, B.; Gonzalo, J.A.; Cross, L.E.; Guo, R.; Park, S.E.; Cox, D.E.; Shirane, G. Tetragonal-to-monoclinic phase transition in a ferroelectric perovskite: The structure of $\mathrm{PbZr}_{0.52} \mathrm{Ti}_{0.48} \mathrm{O}_{3}$. Phys. Rev. B. 2000, 61, doi:10.1103/PhysRevB.61.8687.

4. Park, S.E.; Shrout, T.R. Ultrahigh strain and piezoelectric behavior in relaxor based ferroelectric single crystals. J. Appl. Phys. 1997, 82, 1804-1811.

5. Yamashita, Y. Large electromechanical coupling factors in perovskite binary material system. Jpn. J. Appl. Phys. 1994, 33, 5328-5331.

6. Smolenskii, G.A.; Isupov, V.A.; Agranovskaya, A.I.; Kainik, N.N. New ferroelectrics of complex composition. Sov. Phys. Solid State 1961, 2, 2651-2654.

7. Smolenskii, G.A.; Isupov, V.A.; Agranovskaya, A.I.; Popov, S.B. Ferroelectrics with diffuse phase transitions. Sov. Phys. Solid State 1961, 2, 2584-2594.

8. Cross, L.E. Relaxor ferroelectrics. Ferroelectrics 1987, 76, 241-267.

9. Kuwata, J.; Uchino, K.; Nomura, S. Phase transitions in PZN-PT system. Ferroelectrics 1981, 37, 579-582.

10. Kuwata, J.; Uchino, K.; Nomura, S. Dielectric and piezoelectric properties of 0.91PZN-0.09PT single crystals. Jpn. J. Appl. Phys. 1982, 21, 1298-1302.

11. Shrout, T.R.; Chang, Z.P.; Kim, N.; Markgraf, S. Dielectric behavior of single crystals near the $(1-x)$ PMN-xPTmorphotropic phase boundary. Ferroelectr. Lett. 1990, 12, 63-69.

12. Park, S.; Hackenberger, W. High performance single crystal piezoelectrics: Applications and issues. Cur. Opin. Solid State Mater. Sci. 2002, 6, 11-18.

13. Park, S.E.; Shrout, T.R. Characteristics of relaxor-based piezoelectric single crystals for ultrasonic transducers. IEEE Trans. Ultrason. Ferroelectr. Freq. Control 1997, 44, 1140-1147.

14. Park, S.E.; Shrout, T.R. Relaxor based ferroelectric single crystals for electro-mechanical actuators. Mater. Res. Innovat. 1997, 1, 20-25.

15. Shin, M.C.; Shung, S.J.; Lee, S.-G.; Feigelson, R.S. Growth and observation of domain structure of lead magnesium niobate-lead titanate single crystals. J. Cryst. Growth 2003, 263, 412-420.

16. Zawilski, K.T.; Claudia, M.; Custodio, C.; Demattei, R.C.; Lee, S.-G.; Monteiro, R.G.; Odagawa, H.; Feigelson, R.S. Segregation during the vertical Bridgman growth of lead magnesium niobate single crystals. J. Cryst. Growth 2003, 258, 353-367.

17. Zhang, K.C.; Zhang, L.H. Science and Technology of Crystal Growth, 2nd ed.; Science Press: Beijing, China, 1997.

18. Chen, W.; Ye, Z.-G. Top seeded solution growth and characterization of piezo-/ferroelectric $(1-x) \mathrm{Pb}\left(\mathrm{Zn}_{1 / 3} \mathrm{Nb}_{2 / 3}\right) \mathrm{O}_{3}-x \mathrm{PbTiO}_{3}$ single crystals. J. Cryst. Growth 2001, 233, 503-511.

19. Harada, K.; Hosono, Y.; Yamashita, Y.; Miwa, K. Piezoelectric $\mathrm{Pb}\left[\left(\mathrm{Zn}_{1 / 3} \mathrm{Nb}_{2 / 3}\right)_{0.91} \mathrm{Ti}_{0.09}\right] \mathrm{O}_{3}$ single crystals with a diameter of 2 inches by the solution Bridgman method supported on the bottom of a crucible. J. Cryst. Growth 2001, 229, 294-298.

20. Lee, S.-G.; Monteiro, R.G.; Feigelson, R.S.; Lee, H.S.; Lee, M.; Park, S.-E. Growth and electrostrictive properties of $\mathrm{Pb}\left(\mathrm{Mg}_{1 / 3} \mathrm{Nb}_{2 / 3}\right) \mathrm{O}_{3}$ crystals. Appl. Phys. Lett. 1999, 74, 1030-1032.

21. Dong, M.; Ye, Z.-G. High temperature solution growth and characterization of piezo-/ferroelectric PMNT single crystals. J. Cryst. Growth 2000, 209, 81-90.

22. Luo, H.; Xu, G.; Wang, P.; Yin, Z. Growth and characterization of relaxor ferroelectric PMNT single crystals. Ferroelectrics 1999, 231, 685-690. 
23. Luo, H.; Xu, G.; Xu, H.; Wang, P.; Yin, Z. Compositional homogeneity and electrical properties of lead magnesium niobate titanate single crystals grown by a modified bridgman technique. $J$. Appl. Phys. 2000, 39, 5581-5585.

24. Swartz, S.L.; Shrout, T.R. Fabrication of perovskite lead magnesium niobate. Mater. Res. Bull. 1982, $17,1245-1250$.

25. Watanabe, A.; Haneda, H.; Mariyoshi, Y.; Shirasaki, S.; Kuramoto, S.; Yamamura, H. Preparation of lead magnesium niobate by a coprecipitation method. J. Mater. Sci. 1992, 27, 1245-1249.

26. Yoon, K.H.; Cho, Y.S.; Kang, D.H. The formation and phase stability of lead magnesium niobate in the presence of a molten flux. J. Mater. Sci. 1995, 30, 4244-4248.

27. Zawilski, K.T.; DeMattei, R.C.; Feigelson, R.S. Zone leveling of lead magnesium niobate-lead titanate crystals using RF heating. J. Cryst. Growth 2005, 277, 393-400.

28. Hackenberger, W.S.; Luo, J.; Jiang, X.; Snook, K.A.; Rehrig, P.W. Handbook of Advanced Dielectric, Piezoelectric and Ferroelectric Materials; Ye, Z.-G., Ed.; CRC Press: Boca Raton, FL, USA, 2008.

29. Guo, Y.; Luo, H.; Ling, D.; Xu, H.; He, T.; Yin, Z. Effect of a bias field on the dielectric properties of $0.69 \mathrm{~Pb}\left(\mathrm{Mg}_{1 / 3} \mathrm{Nb}_{2 / 3}\right) \mathrm{O}_{3}-0.31 \mathrm{PbTiO}_{3}$ single crystals with different orientations. $J$. Phys. Condens. Matter 2003, 15, 6899-6908.

30. Guo, Y.; Luo, H.; Chen, K.; Xu, H.; Yin, Z. Effect of composition and poling field on the properties and ferroelectric phase-stability of $\mathrm{Pb}\left(\mathrm{Mg}_{1 / 3} \mathrm{Nb}_{2 / 3}\right) \mathrm{O}_{3}-\mathrm{PbTiO}_{3}$ crystals. J. Appl. Phys. 2002, 92, 6134-6138.

31. Davis, M.; Damjanovic, D.; Setter, N. Electric-field-, temperature-, and stress-induced phase transitions in relaxor ferroelectric single crystals. Phys. Rev. B 2006, 73, doi:10.1103/ PhysRevB.73.014115.

32. Mutsushima, M.; Tachi, Y.; Iwasaki, Y. JFE Technical Report; JFE Holdings, Inc.: Tokyo, Japan, 2005.

33. Ye, Z.-G. High-performance piezoelectric single crystals of complex perovskite solid solutions. MRS Bull. 2009, 34, 277-283.

34. Pfann, W.G. Zone Melting, 2nd ed.; Wiley: New York, NY, USA, 1966.

35. Echizenya, K.; Matsushita, M.; Tachi, Y.; Addona, T. Characterization of PMN-PT single crystals grown by continuous feed technique. In Abstract Book of 2010 U.S. Navy Workshop on Acoustic Transduction Materials and Devices; Penn State University: State College, PA, USA, 2010.

36. Shrout, T.R.; Eitel, R.E.; Randall, C.A. Piezoelectric Materials in Devices; Setter, N., Ed.; Swiss Federal Institute of Technology: Lausanne, Switzerland, 2002.

37. Randall, C.A.; Eitel, R.E.; Stringer, C.; Song, T.H.; Zhang, S.J.; Shrout, T.R. Piezoelectric Single Crystals and Their Applications; Trolier-McKinstry, S., Cross, L.E., Yamashita, Y., Eds.; Pennsylvania State Univeristy: University Park, PA, USA, 2004.

38. Mitsui, T.; Nomura, S. Ferroelectrics and Related Substances; Springer-Verlag: Berlin, Germany, 1981.

39. Yamashita, Y.; Harada, K. Crystal growth and electrical properties of lead scandium niobate-lead titanate binary single crystals. Jpn. J. Appl. Phys. 1997, 36, 6039-6042.

40. Yamashita, Y.; Shimanuki, S. Synthesis of lead scandium niobate-lead titanate pseudo binary system single crystals. Mater. Res. Bull. 1996, 31, 887-895. 
41. Bing, Y.H.; Ye, Z.G. Effects of chemical compositions on the growth of relaxor ferroelectric $\mathrm{Pb}\left(\mathrm{Sc}_{1 / 2} \mathrm{Nb}_{1 / 2}\right)_{1-x} \mathrm{Ti}_{x} \mathrm{O}_{3}$ single crystals. J. Cryst. Growth 2003, 250, 118-125.

42. Yasuda, N.; Ohwa, H.; Kume, M.; Hayashi, K.; Hosono, Y.; Yamashita, Y. Crystal growth and electrical properties of lead indium niobate-lead titanate binary single crystal. J. Cryst. Growth 2001, 229, 299-304.

43. Yasuda, N.; Mori, N.; Ohwa, H.; Hosono, Y.; Yamashita, Y.; Iwata, M.; Maeda, M.; Suzuki, I.; Ishibashi, Y. Crystal growth and some properties of lead indium niobate-lead titanate single crystals produced by solution bridgman method. Jpn. J. Appl. Phys. 2002, 41, 7007-7010.

44. Guo, Y.; Luo, H.; He, T.; Pan, X.; Yin, Z. Electric-field-induced strain and piezoelectric properties of a high Curie temperature $\mathrm{Pb}\left(\mathrm{In}_{1 / 2} \mathrm{Nb}_{1 / 2}\right) \mathrm{O}_{3}-\mathrm{PbTiO}_{3}$ single crystal. Mater. Res. Bull. 2003, 38, 857-864.

45. Zhang, S.J.; Rehrig, P.W.; Randall, C.A.; Shrout, T.R. Crystal growth and electrical properties of $\mathrm{Pb}\left(\mathrm{Yb}_{1 / 2} \mathrm{Nb}_{1 / 2}\right) \mathrm{O}_{3}-\mathrm{PbTiO}_{3}$ perovskite single crystals. J. Crys. Growth 2002, 234, 415-420.

46. Zhang, S.J.; Rhee, S.; Randall, C.A.; Shrout, T.R. Dielectric and piezoelectric properties of high curie temperature single crystals in the $\mathrm{Pb}\left(\mathrm{Yb}_{1 / 2} \mathrm{Nb}_{1 / 2}\right) \mathrm{O}_{3}-x \mathrm{PbTiO}_{3}$ solid solution series. Jpn. J. Appl. Phys. 2002, 41, 722-726.

47. Zhang, S.J.; Randall, C.A.; Shrout, T.R. High Curie temperature piezocrystals in the $\mathrm{BiScO}_{3}-\mathrm{PbTiO}_{3}$ perovskite system. Appl. Phys. Lett. 2003, 83, 3150-3152.

48. Zhang, S.J.; Randall, C.A.; Shrout, T.R. Dielectric, piezoelectric and elastic properties of tetragonal $\mathrm{BiScO}_{3}-\mathrm{PbTiO}_{3}$ single crystal with single domain. Solid State Commun. 2004, 131, 41-45.

49. Yasuda, N.; Ohwa, H.; Hasegawa, D.; Hosono, H.; Yamashita, Y.; Iwata, M.; Ishibashi, Y. Dielectric and piezoelectric properties of lead indium niobate-lead titanate single crystal with high curie temperature near morphotropic phase boundary. Ferroelectrics 2002, 270, 247-252.

50. Zhang, S.J.; Randall, C.A.; Shrout, T.R. Characterization of perovskite piezoelectric single crystals of $0.43 \mathrm{BiScO}_{3}-0.57 \mathrm{PbTiO}_{3}$ with high Curie temperature. J. Appl. Phys. 2004, 95, 4291-4295.

51. Luo, J.; Hackenberger, W.; Zhang, S.; Shrout, T.R. Advances in manufacturing relaxor piezoelectric single crystals. In Abstract Book of 2007 U.S. Navy Workshop on Acoustic Transduction Materials and Devices; Pennsylvania State University: University Park, PA, USA.

52. Lee, S.-M.; Kim, D.-H.; Lee, H.-Y. Development of high performance piezoelectric single crystals of PZT-based compositions. In Abstract Book of 2007 U.S. Navy Workshop on Acoustic Transduction Materials and Devices; Pennsylvania State University: University Park, PA, USA.

53. Zhang, S.J.; Lee, S.M.; Kim, D.H.; Lee, H.Y.; Shrout, T.R. Characterization of high $T_{\mathrm{C}}$ PMN-PZ-PT single crystals fabricated by solid state crystal growth. Appl. Phys. Lett. 2007, 90, 232911:1-232911:3.

54. He, C.; Li, X.Z.; Wang, Z.J.; Liu, Y.; Shen, D.Q.; Li, T.; Long, F. Compositional dependence of properties of $\mathrm{Pb}\left(\mathrm{Yb}_{1 / 2} \mathrm{Nb}_{1 / 2}\right) \mathrm{O}_{3}-\mathrm{Pb}\left(\mathrm{Mg}_{1 / 3} \mathrm{Nb}_{2 / 3}\right) \mathrm{O}_{-3}-\mathrm{PbTiO}_{3}$ ternary ferroelectric crystals. CrystEngComm 2012, 14, 4513-4519.

55. He, C.; Li, X.Z.; Wang, Z.J.; Liu, Y.; Shen, D.Q.; Li, T.; Long, X.F.; Mao, S.Y.; Ye, Z.-G. Preparation and characterization of new $\mathrm{Pb}\left(\mathrm{Yb}_{1 / 2} \mathrm{Nb}_{1 / 2}\right) \mathrm{O}_{3}-\mathrm{Pb}\left(\mathrm{Mg}_{1 / 3} \mathrm{Nb}_{2 / 3}\right) \mathrm{O}_{-3}-\mathrm{PbTiO}_{3}$ Ternary Piezo-/Ferroelectric crystals. Chem. Mater. 2010, 22, 5588-5592. 
56. Li, T.; Tailor, H.; Li, X.Z.; Wang, Z.J.; Liu, Y.; He, C.; Chu, T.; Ai, L.D.; Pang, D.F.; Long, X.F. Top-seeded solution growth and properties of high $T_{\mathrm{C}} \mathrm{Pb}\left(\mathrm{In}_{1 / 2} \mathrm{Nb}_{1 / 2}\right) \mathrm{O}_{3}-\mathrm{Pb}\left(\mathrm{Zn}{ }_{1 / 3} \mathrm{Nb}_{2 / 3} \mathrm{O}_{3}-\mathrm{PbTiO}_{3}\right.$ single crystals. Sci. Adv. Mater. 2013, 5, 1271-1274.

57. He, C.; Li, X.Z.; Wang, Z.J.; Liu, Y.; Shen, D.Q.; Li, T.; Long, X.F.; Ye, Z.-G. Growth of $\mathrm{Pb}\left(\mathrm{Fe}_{1 / 2} \mathrm{Nb}_{1 / 2}\right) \mathrm{O}_{3}-\mathrm{Pb}\left(\mathrm{Yb}_{1 / 2} \mathrm{Nb}_{1 / 2}\right) \mathrm{O}_{3}-\mathrm{PbTiO}_{3}$ piezo-/ferroelectric crystals for high power and high temperature applications. CrystEngComm 2012, 14, 4407-4413.

58. Zhang, S.-J.; Lee, S.-M.; Kim, D.-H.; Lee, H.-Y.; Shrout, R.T. Elastic, piezoelectric, and dielectric properties of $0.71 \mathrm{~Pb}\left(\mathrm{Mg}_{1 / 3} \mathrm{Nb}_{2 / 3}\right) \mathrm{O}_{3}-0.29 \mathrm{PbTiO}_{3}$ crystals obtained by solid-state crystal growth. J. Am. Ceram. Soc. 2008, 91, 683-686.

59. Luo, J.; Hackenberger, W.; Zhang, S.; Shrout, T.R. Elastic, piezoelectric and dielectric properties of PIN-PMN-PT crystals grown by bridgman method. In Proceeding of the IEEE International Ultrasonics Symposium Proceedings, Beijing, China, 2-5 November 2008.

60. Davis, M.; Damjanovic, D.; Hayem, D.; Setter, N. Domain engineering of the transverse piezoelectric coefficient in perovskite ferroelectrics. J. Appl. Phys. 2005, 98, 014102:1-014102:9.

61. Zhang, S.J.; Sherlock, N.P.; Meyer, R.J., Jr.; Shrout, T.R. Crystallographic dependence of loss in domain engineered Relaxor-PT single crystals. Appl. Phys. Lett. 2009, 94, 162906:1-162906:3.

62. Damjaonvic, D.; Budimir, M.; Davis, M.; Setter, N. Piezoelectric anisotropy: Enhanced piezoelectric response along nonpolar directions in perovskite crystals. J. Mater. Sci. 2006, 41, $65-76$.

63. Davis, M. Phase Transitions, Anisotropy and Domain Engineering: The Piezoelectric Properties of Relaxor-Ferroelectric Single Crystals. Ph.D. Thesis, Ceramics Laboratory, Swiss Federal Institute of Technology, Lausanne, Switzland, 19 May 2006.

64. Zhang, S.J.; Randall, C.A.; Shrout, T.R. Electromechanical propertiesin rhombohedral $\mathrm{BiScO}_{3}-\mathrm{PbTiO}_{3}$ single crystals as a function of temperature. Jpn. J. Appl. Phys. 2003, 42, L1152-L1154.

65. Peng, J.; Luo, H.; Lin, D.; Xu, H.; He, T.; Jin, W. Orientation dependence of transverse piezoelectric properties of $0.70 \mathrm{~Pb}\left(\mathrm{Mg}_{1 / 3} \mathrm{Nb}_{2 \beta}\right) \mathrm{O}_{3}-0.30 \mathrm{PbTiO}_{3}$ single crystals. Appl. Phys. Lett. 2004, 85, 6221-6223.

66. Zhang, R.; Jiang, B.; Jiang, W.H.; Cao, W.W. Complete set of elastic, dielectric, and piezoelectric coefficients of $0.93 \mathrm{~Pb}\left(\mathrm{Zn}_{1 / 3} \mathrm{Nb}_{2 / 3}\right) \mathrm{O}_{3}-0.07 \mathrm{PbTiO}_{3}$ single crystal poled along [011]. Appl. Phys. Lett. 2006, 89, 242908:1-242908:3.

67. Shanthi, M.; Lim, L.C.; Rajan, K.K.; Jin, J. Complete sets of elastic, dielectric, and piezoelectric properties of flux-grown [011]-poled $\mathrm{Pb}\left(\mathrm{Mg}_{1 / 3} \mathrm{Nb}_{2 / 3}\right) \mathrm{O}_{3}-(28-32) \% \mathrm{PbTiO}_{3}$ single crystals. Appl. Phys. Lett. 2008, 92, 142906:1-142906:3.

68. Zhang, S.J.; Lee, S.M.; Kim, D.H.; Lee, H.Y.; Shrout, T.R. Temperature dependence of the dielectric, piezoelectric, and elastic constants for piezocrystals. J. Appl. Phys. 2007, 102, 114103:1-114103:5.

69. Zhang, S.J.; Luo, J.; Hackenberger, W.; Sherlock, N.P.; Meyer, R.J., Jr.; Shrout, T.R. Electromechanical characterization of $\mathrm{PbIn}_{0.5} \mathrm{Nb}_{0.5} \mathrm{O}_{3}-\mathrm{PbMg}_{1 / 3} \mathrm{Nb}_{2 / 3} \mathrm{O}_{3}-\mathrm{PbTiO}_{3}$ crystals as a function of crystallographic orientation and temperature. J. Appl. Phys. 2009, 105, 104506:1-104506:5.

70. IEEE Standard on Piezoelectricity; ANSI/IEEE Std 176-1987; IEEE: New York, NY, USA, 1987. 
71. Zhang, R.; Jiang, B.; Cao, W.W. Elastic, piezoelectric, and dielectric properties of multidomain $0.67 \mathrm{~Pb}\left(\mathrm{Mg}_{1 / 3} \mathrm{Nb}_{2 / 3}\right) \mathrm{O}_{3}-0.33 \mathrm{PbTiO}_{3}$ single crystals. J. Appl. Phys. 2001, 90, 3471-3475.

72. Zhang, S.J.; Luo, J.; Hackenberger, W.; Shrout, T.R. Characterization of $\mathrm{Pb}\left(\mathrm{In}_{1 / 2} \mathrm{Nb}_{1 / 2}\right) \mathrm{O}_{3^{-}}$ $\mathrm{Pb}\left(\mathrm{Mg}_{1 / 3} \mathrm{Nb}_{2 / 3} \mathrm{O}_{3}-\mathrm{PbTiO}_{3}\right.$ ferroelectric crystal with enhanced phase transition temperatures. $J$. Appl. Phys. 2008, 104, 064106:1-064106:5.

73. Luo, J.; Zhang, S.J.; Hackenberger, W.; Shrout, T.R. A high QM Relaxor ferroelectric single crystal: Growth and characterization. In Proceeding of the 2010 IEEE International Ultrasonics Symposium, San Diego, CA, USA, 11-14 October 2010.

74. Wang, F.F.; Luo, L.H.; Zhou, D. Complete set of elastic, dielectric, and piezoelectric constants of orthorhombic $0.71 \mathrm{~Pb}\left(\mathrm{Mg}_{1 / 3} \mathrm{Nb}_{2 / 3}\right) \mathrm{O}_{3}-0.29 \mathrm{PbTiO}_{3}$ single crystal. Appl. Phys. Lett. 2007, 90, 212903:1-212903:3.

75. Sun, E.W.; Zhang, S.J.; Luo, J.; Shrout, T.R.; Cao, W.W. Complete set of elastic, dielectric, and piezoelectric constants of [011] poled rhombohedral $\mathrm{Pb}\left(\mathrm{In}_{1 / 2} \mathrm{Nb}_{1 / 2}\right) \mathrm{O}_{3}-\mathrm{Pb}\left(\mathrm{Mg}_{1 / 3} \mathrm{Nb}_{2 / 3}\right) \mathrm{O}_{3}-\mathrm{PbTiO}_{3}: \mathrm{Mn}$ single crystals. J. Appl. Phys. 2013, 113, 074106:1-074106:4.

76. Huo, X.Q.; Zhang, S.J.; Liu, G.; Zhang, R.; Luo, J.; Sahul, R.; Cao, W.W.; Shrout, T.R. Elastic, dielectric and piezoelectric characterization of [011] poled rhombohedral PIN-PMN-PT:Mn crystals. J. Appl. Phys. 2012, 112, 124113:1-124113:5.

77. Liu, X.Z.; Zhang, S.J.; Luo, J.; Shrout, T.R.; Cao, W.W. The characterization of single-domain $\mathrm{Pb}\left(\mathrm{In}_{1 / 2} \mathrm{Nb}_{1 / 2}\right) \mathrm{O}_{3}-\mathrm{Pb}\left(\mathrm{Mg}_{1 / 3} \mathrm{Nb}_{2 / 3}\right) \mathrm{O}_{3}-\mathrm{PbTiO}_{3}$ ferroelectric crystal. Appl. Phys. Lett. 2010, 96, doi:10.1063/1.3275803.

78. Powers, J.M.; Viehland, D.; Ewart, L. Property measurements on piezoelectric single crystals and the implications for transducer design, smart structure and materials. In Proceedings of the SPIE, Newport Beach, CA, USA, 11 July 2001.

79. Montgomery, T.C.; Meyer, R.J., Jr.; Bienert, E.M. Broadband transduction implementation and system impact. In Proceeding of the OCEANS, Vancouver, BC, USA, 29 September-4 October 2007.

80. Janolin, P.-E.; Dkhil, B.; Davis, M.; Damjanovic, D.; Setter, N. Uniaxial-stress induced phase transition in [001] cpoled $0.955 \mathrm{pb}\left(\mathrm{Zn}_{1 / 3} \mathrm{Nb}_{2 / 3}\right) \mathrm{O}_{3}-0.045 \mathrm{PbTiO}_{3}$. Appl. Phys. Lett. 2007, 90, doi:10.1063/1.2721856.

81. Shanthi, M.; Lim, L.C. Combined electric field and stress-induced R-O phase transformation in [011]-poled $\mathrm{Pb}\left(\mathrm{Mg}_{1 / 3} \mathrm{Nb}_{2 / 3}\right) \mathrm{O}_{3}-(28-32) \% \mathrm{PbTiO}_{3}$ single crystals of [011] -length cut. Appl. Phys. Lett. 2009, 95, 102901:1-102901:3.

82. Okawara, C.; Amin, A. DC field effect on stability of piezoelectric PZN-0.06PT single crystals under compressive stress. Appl. Phys. Lett. 2009, 95, 072902:1-072902:3.

83. Finkel, P.; Robinson, H.; Stace, J.; Amin, A. Study of phase transitions in ternary lead indium niobate-lead magnesium niobate-lead titanaterelaxor ferroelectric morphotropic single crystals. Appl. Phys. Lett. 2010, 97, 122903:1-122903:3.

84. Finkel, P.; Benjamin, K.; Amin, A. Large strain transduction utilizing phase transition in relaxor-ferroelectric $\mathrm{Pb}\left(\mathrm{In}_{1 / 2} \mathrm{Nb}_{1 / 2}\right) \mathrm{O}_{3}-\mathrm{Pb}\left(\mathrm{Mg}_{1 / 3} \mathrm{Nb}_{2 / 3}\right) \mathrm{O}_{3}-\mathrm{PbTiO}_{3}$ single crystals. Appl. Phys. Lett. 2011, 98, 192902:1-192902:3.

85. Zhang, S.J.; Taylor, S.; Li, F.; Luo, J.; Meyer, R., Jr. Piezoelectric property of relaxor-PbTiO 3 crystals under uniaxial transverse stress. Appl. Phys. Lett. 2013, 102, 172902:1-172902:5. 
86. Luo, J.; Zhang, S.J.; Taylor, S.; Hackenberger, W. Large field property assessment of Mn:PIN-PMNPT crystals for high power transducers. In Proceeding of the IEEE International Symposium on the 2013 ISAF, State College, PA, USA, 21-25 July 2013.

87. Sherlock, N.P.; Meyer, R., Jr. Modified single crystals for high-power underwater projectors. IEEE Trans.Ultrason. Ferroelectr. Freq. Control 2012, 59, 1285-1291.

88. Sherlock, N.P.; Zhang, S.J.; Luo, J.; Lee, H.-Y.; Shrout, T.R.; Meyer, R., Jr. Large signal electromechanical properties of low loss $(1-x) \mathrm{Pb}\left(\mathrm{Mg}_{1 / 3} \mathrm{Nb}_{2 / 3}\right) \mathrm{O}_{3}-x \mathrm{PbTiO}_{3}$ single crystals. J. Appl. Phys. 2010, 107, 074108:1-074108:5.

89. Zhang, S.J.; Li, F. High performance ferroelectric relaxor-PT single crystals: Status and perspective. J. Appl. Phys.2012, 111, 031301:1-031301:50.

(C) 2014 by the authors; licensee MDPI, Basel, Switzerland. This article is an open access article distributed under the terms and conditions of the Creative Commons Attribution license (http://creativecommons.org/licenses/by/3.0/). 